\title{
Modelling of Reinforced Concrete Slabs in Fire
}

Yong Wang ${ }^{\text {a,b }}$, Guanglin Yuan ${ }^{\text {a }}$, Zhaohui Huang ${ }^{\mathrm{c}, *}$, Junli Lyu ${ }^{\mathrm{d}}$, Qingtao Li ${ }^{\mathrm{a}}$, Bangyun Long ${ }^{\mathrm{a}}$

a Jiangsu Key Laboratory of Environmental Impact and Structural Safety in Engineering, China University of Mining and Technology, Xuzhou, Jiangsu 221116;

b State Key Laboratory for Geomechanics and Deep Underground Engineering, China University of Mining and Technology, Xuzhou, Jiangsu 221116, China;

c Department of Civil and Environmental Engineering, Brunel University, Uxbridge, Middlesex UB8 3PH, UK;

d School of Civil Engineering, Shandong Jianzhu University, Jinan, China

\begin{abstract}
A numerical procedure for the thermal analysis of RC slabs at elevated temperatures is the subject of this study, where the moisture increase due to the so-called moisture clog occurring in the cooler parts of reinforced concrete (RC) slabs is introduced as well. Starting from a systematic investigation on the existing concrete constitutive laws available in the literature and in the codes, improved concrete constitutive laws are proposed to describe concrete thermal and mechanical properties at elevated temperatures. The proposed laws - called also models - are validated against well-documented full- and small-scale tests on simply-supported RC slabs. Parametric analyses on the behaviour of RC slabs in fire are carried out as well, to clarify the role that the different constitutive laws may have in the numerical prediction of RC slabs behaviour under fire conditions.
\end{abstract}

Keywords: Reinforced concrete slab; Fire resistance; Numerical analysis; Concrete constitutive laws; Moisture content

c,* Corresponding author.

E-mail address: zhaohui.huang@brunel.ac.uk (Z. Huang) 


\section{Highlights:}

Develop a numerical procedure for the thermal analysis of RC slabs in fire;

Propose concrete constitutive laws for the analysis of RC slabs in fire;

Validate the proposed models against previous fire tests on simply-supported RC slabs;

$>$ Carry out parametric analyses on the behaviour of RC slabs in fire. 


\section{Introduction}

In recent years, several full-scale fire tests of reinforced concrete $(\mathrm{RC})$ slabs were conducted to investigate the influence of the tensile membrane action on the behaviour of floor slabs. However, due to the huge costs and complexities associated with the full-scale fire tests, a number of numerical models have been developed by various researchers to predict the fire response of concrete slabs [1-5].

When modelling the behaviours of the slabs in fire, it is very important to accurately and efficiently determine the temperature distribution within the slabs. So far, two main calculation methods have been commonly used to predict the temperature distributions of RC slabs: a combined heat and mass transfer analysis and a heat transfer analysis only.

In 1998, Hurst and Ahmed [6] developed and numerically solved a mathematical model to predict heat and mass transfer in concrete structures subjected to fire. The model simulates the changes in pore pressure, temperature and moisture with corresponding changes in concrete properties and has also been able to predict moisture clog. In 2001, Tenchev et al. [7] proposed a comprehensive coupled heat-and-mass transfer model to predict the pore pressures and the moisture migration within concrete at elevated temperatures. In 2003, Gawin et al. [8] developed one mathematical model to predict the pore pressure, moisture transfer and evaporation within concrete at high temperatures. In 2009, Dwaikat and Kodur [9] developed one-dimensional numerical model to predict the fire-induced spalling and pore pressure in concrete structures based on principles of mechanics and thermodynamics. Although these models are capable of predicting moisture concentrations and pore pressures, they are complex and expensive to process. For instance, moisture evaporation or migration is a complex process and depends on many material properties, such as the porosity and permeability of concrete, which are not well known at elevated temperatures. Thus, very often the use of simpler, faster models, which are capable of predicting temperatures with reasonable accuracy, is valid. This is especially true if concrete spalling is unlikely and the moisture can migrate to an unheated surface and escape.

As a matter of fact, under physically realistic conditions, if only the temperatures of slabs are required for the structural analysis, a simple approach, in which the effect of moisture is treated explicitly, can be used to predict the temperature distribution of the slabs in fire. For instance, Wickstrom [10] used a modified enthalpy curve applying an average slope to take into account the effect of moisture subjected to evaporation in concrete. Huang et al. [11] proposed a model based on the theoretical heat and mass transfer in concrete. Lamont et al. [12] developed one adaptive heat transfer program HADAPT and considered moisture evaporation by using an enthalpy method. 
However, the predicted temperatures do not show a pronounced plateau at $100^{\circ} \mathrm{C}$ due to neglecting the localised moisture concentrations. For thermal analysis, Bisby and Kodur [13-14] assumed that moisture begins to evaporate from an element when its temperature reaches $100{ }^{\circ} \mathrm{C}$, and the temperature of the element remains $100{ }^{\circ} \mathrm{C}$ until the moisture has evaporated. In 2007, Capua and Mari [15] proposed that the effect of moisture was taken into account using the concept of enthalpy by defining a water vapour function to describe the evolution of the latent heat of evaporation. In 2011, Zhang [16] investigated the weight loss of concrete specimens exposed to various heating temperatures together with various exposure times. Results show that weight loss increased significantly between $150{ }^{\circ} \mathrm{C}$ and $250{ }^{\circ} \mathrm{C}$ due to evaporation of capillary water and gel water. In all, in terms of obtaining temperature data as input for a structural analysis, a simple approach including moisture evaporation but ignoring moisture migration may be well suitable. A slightly conservative estimate of the real temperatures will be achieved because the high localised moisture concentrations, experienced near the dry-wet interface are ignored.

Apart from the thermal analysis, the structural behaviour of RC slabs also depends on the mechanical properties of concrete at elevated temperatures. Hence, the knowledge of temperature-dependent properties of concrete is critical for the assessment of fire-resistant performance of RC slabs. A review of the literature shows that the material laws of concrete are mainly influenced by the aggregate type [17-19]. However, it is interesting to note that there are different points of view on this issue. For example, the models proposed in Eurocode 2 (EC2) [17] have the same heat capacity for both siliceous and calcareous aggregate concrete. EC2's model provides two limits for the thermal conductivity of concrete without making reference to concrete types. Meanwhile, EC2's law distinguishes between the concrete types for thermal elongation only. In contrast, ASCE code (ASCE) [18, 19] presents the different thermal relationships for the siliceous and calcareous concrete, but without considering the effect of concrete types on their mechanical properties.

Since there are no universally acceptable constitutive relationships available for concrete at high temperature, several uniaxial laws of concrete at elevated temperatures were proposed in the literature, particularly the transient strain. In 2005, based on the available relationships for the mechanical behaviour of concrete at elevated temperatures, $\mathrm{Li}$ and Purkiss [20] proposed a stress-strain-temperature law which incorporated the effect of transient strain implicitly. In 2007, according to the review of the existing laws for concrete at elevated temperatures, two general stress-strain relationships were proposed by Youssef and Moftah [21]. In these concrete material laws the transient strain is modelled by shifting the strain at maximum stress. However, the two laws can hardly be used in the structural analysis of RC members in fire, due to their complexities. 
In 2008, Law and Gillie [22] reported that considering the transient strain implicitly can have an important influence on the Young's modulus calculation of concrete. In 2012, based on EC2, Gernay and Franssen [23] proposed a new formulation of EC2 concrete material law (ETC law) that contains an explicit term for transient strain. Comparing the different constitutive laws leads to the conclusion that it is preferable to consider the transient strain explicitly. However, the main parameters of the ETC law are based on those of siliceous concrete at elevated temperatures (EC2 law). In addition, in 2013, Gernay et al. [24] developed a multiaxial constitutive model for concrete based on a plastic-damage formulation and considered the effect of transient creep strain explicitly.

In 2016, Torelli et al. [25] systemically reviewed experimental and analytical works on the load-induced thermal strain (LITS) component, discussed the necessity for explicitly modelling the LITS component in the numerical simulations as well as its physical mechanism. In 2017, Torelli et al. [26] presented a novel 3D LITS model to be used for concrete subjected to transient temperatures up to $250^{\circ} \mathrm{C}$ and investigated that the development of LITS significantly influences the stress redistribution in the structure. Previous studies indicated that accurate and robust constitutive models are crucial for reliably assessing the fire behaviour of concrete structures. However, the simplified models for practical applications in real structural fire engineering design are urgently required [25-27]. Hence, developing a general-purpose constitutive model for concrete in fire may still be considered as an open issue. At present, very limited research has been conducted to assess the influence of different concrete constitutive models on the analysis of RC members in fire [27].

Therefore, the main objectives of this paper are to:

- Develop a simplified numerical procedure for the thermal analysis of RC slabs at elevated temperatures. In the proposed model the moisture increase due to the moisture clog within the cooler part of cross-section of RC member is considered.

- Conduct a systematic investigation on the existing concrete constitutive laws, which are proposed by current design codes and literature. Based on this study, some shortcomings of the existing constitutive models recommended in the current design codes are revealed and discussed. Also more accurate concrete constitutive laws at elevated temperatures are proposed, in which the stress-strain relationship is mainly based on the model developed by Anderberg and Thelandersson [28]. The accuracy of the proposed models is validated by modelling a series of well-documented full-scale and small-scale fire tests on the simply supported RC slabs.

- Conduct a series of parametric studies to understand the effects of concrete material laws on 
the fire performance of RC slabs.

\section{Development of a simplified thermal analysis model}

\subsection{Assumptions}

In this study, the main assumptions for the development of the thermal analysis models are:

(1) For the calculation of the temperatures of RC slabs, the influence of the steel reinforcement is ignored.

(2) Evaporation of water within the RC slabs is considered for predicting temperature distribution. According to the test results, the temperature of boiling water inside the concrete ranges from $100^{\circ} \mathrm{C}$ to $140^{\circ} \mathrm{C}$, and a linear evaporation function is used to consider the evaporation of the water.

(3) The moisture content along the thickness of concrete slab is assumed to be a simple function of the temperature.

(4) Spalling of concrete is not considered in the heat transfer analysis.

\subsection{Governing equations}

Using above assumptions, the energy equation within the concrete can be expressed as [15]:

$$
\rho(T) c(T) \frac{\partial T}{\partial t}+\frac{\partial L_{w}}{\partial t}=\frac{\partial}{\partial x}\left(k(T) \frac{\partial T}{\partial x}\right)+\frac{\partial}{\partial y}\left(k(T) \frac{\partial T}{\partial y}\right)+\frac{\partial}{\partial z}\left(k(T) \frac{\partial T}{\partial z}\right)+Q
$$

where: $T$ is the temperature $\left({ }^{\circ} \mathrm{C}\right), t$ is the time $(\mathrm{s}), k(T), \rho(T)$ and $c(T)$ denote the temperature-dependent thermal conductivity $(\mathrm{W} / \mathrm{m} \mathrm{K})$, density $\left(\mathrm{kg} / \mathrm{m}^{3}\right)$ and specific heat capacity $(\mathrm{J} / \mathrm{kg} \mathrm{K})$, respectively, $Q$ is the internal heat generation $(J)$, in the current model it is assumed $Q$ $=0, L_{w}$ is the latent heat function due to the evaporation of water.

Based on Capua's model [15], one modified latent heat function $L_{w}$, which involves the effect of the moisture content, is proposed as:

$$
L_{w}=\rho_{c, 20} m_{\mathrm{w}}(T) w_{0} l_{h 20} f_{w g}(T)
$$

where $\rho_{c, 20}$ is the concrete density at $20^{\circ} \mathrm{C}\left(\mathrm{kg} / \mathrm{m}^{3}\right), w_{0}$ is the initial moisture content by weight $(\%), l_{h 20}$ is the latent heat of evaporation of water $(\mathrm{J} / \mathrm{kg}), f_{w g}(T)$ is the water vapour fraction function, and $m_{\mathrm{w}}(T)$ is the correction function of the initial moisture content. 
The latent heat of evaporation $l_{h 20}$ is defined as [7, 29]:

$$
l_{h 20}=\left\{\begin{array}{cc}
2.8 \times 10^{5} \times(374-T)^{0.368} & T<374^{\circ} \mathrm{C} \\
0 & T \geq 374^{\circ} \mathrm{C}
\end{array}\right.
$$

Eqs. (1) and (2) were used by Capua et al. [15] to predict the temperature of RC columns and the numerical results were compared with test results reported in the literature. It was found that the agreement between the predicted and measured values was not good enough, particularly at the positions of cooler zones of the cross-section. A main reason is that a uniform value of moisture was assumed in the analysis while in reality moisture was higher in the cooler zones of the cross-section due to moisture clog [6].

Hence, in this study, in order to take into account the effect of the non-uniform moisture content on the temperature distributions of RC slabs, the functions $f_{w g}(T)$ and $m_{\mathrm{w}}(T)$ are defined as:

$$
\begin{aligned}
& f_{\mathrm{wg}}(T)= \begin{cases}0 & T<100^{\circ} \mathrm{C} \\
g_{\mathrm{wg}}(T) & 100^{\circ} \mathrm{C} \leq T \leq 140^{\circ} \mathrm{C}, \\
1 & T>140^{\circ} \mathrm{C}\end{cases} \\
& m_{\mathrm{w}}(T)=\left\{\begin{array}{cc}
2.0 & 100^{\circ} \mathrm{C} \leq T \leq 140^{\circ} \mathrm{C} \\
0 & T>140^{\circ} \mathrm{C}
\end{array}\right.
\end{aligned}
$$

where $g_{\mathrm{wg}}(T)$ is a linear function, $m_{\mathrm{w}}(T)$ is the correction function of moisture content. For the slab with large thickness, $m_{\mathrm{w}}(T)$ is assumed to be 2.0. For the thin slab, $m_{\mathrm{w}}(T)$ is equal to 0.0 . These assumptions are supported by previous test results.

According to Eqs. 4(a) and 4(b), the time derivate of $L_{w}$ is obtained as:

$$
\begin{gathered}
\frac{\partial L_{w}}{\partial t}=\frac{\partial L_{w}}{\partial T} \frac{\partial T}{\partial t}=\rho_{c, 20} c^{\prime}(T) \frac{\partial T}{\partial t} \\
c^{\prime}(T)=w_{0}\left[\frac{\partial m_{\mathrm{w}}(T)}{\partial T} l_{\mathrm{h} 20}(T) f_{\mathrm{wg}}(T)+m_{\mathrm{w}}(T) \frac{\partial l_{\mathrm{h} 20}(T)}{\partial T} f_{\mathrm{wg}}(T)+m_{\mathrm{w}}(T) l_{\mathrm{h} 20}(T) \frac{\partial f_{\mathrm{wg}}(T)}{\partial T}\right]
\end{gathered}
$$

Hence, Eq. (1) can be defined as follows:

$$
\rho(T) c(T) \frac{\partial T}{\partial t}+\frac{\partial L_{w}}{\partial t}=\left[\rho(T) c(T)+\rho_{c, 20} c^{\prime}(T)\right] \frac{\partial T}{\partial t}
$$




\subsection{Boundary conditions}

The heat transfer at the exposed and unexposed surfaces of the slab can be depicted by Eq. (7):

$$
-k \frac{\partial T}{\partial n}=h_{c}\left(T-T_{\infty}\right)+\sigma \varepsilon_{r}\left[(T+273)^{4}-\left(T_{\infty}+273\right)^{4}\right]
$$

where $n$ is the outward normal direction of the slab surface, $h_{c}$ is the convective heat transfer coefficient $\left(W /\left(m^{2} K\right)\right), T$ is the surface temperature of the slab $\left({ }^{\circ} \mathrm{C}\right), T_{\infty}$ is the environment temperature $\left({ }^{\circ} \mathrm{C}\right), \sigma$ is the Stefan-Boltzmann constant $\left(5.67 \times 10^{-8} \mathrm{~W} /\left(\mathrm{m}^{2} K^{4}\right)\right)$, and $\varepsilon_{r}$ is the resultant emissivity between fire and exposed surface of slab. In this study, the convection coefficient is assumed to be $h_{c}=30 \mathrm{~W} /\left(\mathrm{m}^{2} \mathrm{~K}\right)$ for the exposed surface of the slab, $h_{c}=10 \mathrm{~W} /\left(\mathrm{m}^{2} \mathrm{~K}\right)$ for the unexposed surface. The resultant emissivity of the exposed surface is assumed to be $\varepsilon_{\mathrm{r}}=0.3$, and $\varepsilon_{\mathrm{r}}=0.2$ is assumed for the unexposed surface.

\subsection{Thermal properties of concrete}

The thermal properties of normal strength concrete are available in both EC2 (Eurocode 2, 2004) [17] and ASCE (ASCE, 1992) [19]. In the current thermal analysis procedure, the thermal properties of concrete are calculated using the laws proposed in EC2 [17]. In addition, spalling was not considered in this paper for simplicity [13-14].

\subsection{Validations}

The thermal analysis model developed above has been incorporated into the computer program developed by the first author [30] for the thermal analysis of RC slabs under fire conditions. In this section, the proposed simplified thermal analysis model is validated by modelling several full-scale and small-scale fire tests of RC slabs. Two full-scale flat slabs, named D147 and 661, tested at the University of Canterbury in New Zealand [31] were used. One full-scale RC slab, named Slab 4ES-2, tested at Shan Dong Jianzhu University in China [32] was also modelled. In addition, 10 small-scale slab tests, named Slabs MF1-MF10 [33], were also used to validate the present models. Some main parameters of these tests are summarised in Table 1. The details of the tests can be found in references [31-33]. Note that, spalling did not occur in these tested slabs.

Figs. 1 to 3 show the comparisons of the predicted and measured temperatures at the various locations through the thickness of the slabs for the entire fire exposure. Generally, reasonable agreements between the predicted and measured temperatures for all slabs were achieved in the validations. Hence, the proposed simplified thermal analysis model in this paper can be used to 
predict the temperatures of RC slabs under fire conditions. Overall, for the full-scale thick slabs, a value of $m_{\mathrm{w}}=2.0$ gives reasonable predictions. Unless otherwise stated, $m_{\mathrm{w}}$ is assumed to be 2.0 in the following analysis, and this assumption is consistent with the theoretical results [6-7]. As shown in Fig. 3 the influence of the moisture content is not significant due to the small thickness of the slab. Hence, it is reasonable to assume $m_{\mathrm{w}}=0$ for the slabs with small thickness.

\section{Development of robust uniaxial concrete constitutive laws at elevated temperatures}

The temperature-dependent material properties of concrete are critically important for analysing the fire response of RC slabs. The mechanical properties of concrete are degraded considerably at elevated temperatures.

\subsection{Stress-strain relationship}

The stress-strain relationship proposed in this paper is mainly based on the law proposed by Anderberg and Thelandersson [28], which is a modification of the conventional stress-strain equation of concrete at ambient temperature. The proposed stress-strain relationship is parabolic for the ascending branch and linear for the descending branch. The ascending branch of the stress-strain curve can be expressed as:

$$
\sigma_{c, T}=f_{c, T}\left[\frac{2 \varepsilon}{\varepsilon_{p, T}}-\frac{\varepsilon^{2}}{\varepsilon_{p, T}^{2}}\right], \quad \varepsilon \leq \varepsilon_{p, T}
$$

where $f_{c, T}$ and $\varepsilon_{p, T}$ are respectively the compressive strength and the strain at the peak stress at temperature $T$.

The Young's modulus of concrete can be calculated as:

$$
E_{c, T}=2 f_{c, T} / \varepsilon_{p, T}
$$

According to Eqs. (8) and (9), the hardening function can be calculated as:

$$
\sigma_{c, e p, T}=-E_{c, T} \varepsilon_{c, e p}+2 \sqrt{E_{c, T} f_{c, T} \varepsilon_{c, e p}}, \quad 0.3 f_{\mathrm{c}, \mathrm{T}}^{\prime}<\sigma_{c, e p, T}<f_{\mathrm{c}, \mathrm{T}}^{\prime}
$$

where $\sigma_{c, e p, T}$ is the effective stress at temperature $T$ and $\varepsilon_{c, e p}$ is the effective plastic strain at temperature $T$.

Figs. 4(a) to 4(e) show the comparisons of the current law with the laws of EC2 [17] and ASCE [19] at different temperatures. It is can be seen that at lower temperatures, there is little difference among 
the three laws. However, the three laws vary considerably when concrete temperature is high (above $400{ }^{\circ} \mathrm{C}$ ). For example, EC2 relationship predicts higher strain at a given stress level or a higher peak strain at given temperature. This indicates that EC2 law predicts a higher ductility. In contrast, the stress-related strains evaluated according to ASCE law are higher than the EC2 and the current models. The comparisons show that ASCE law exhibits the largest stiffness, while EC2 relationship is characterised by high deformability of concrete.

\subsection{Reduction factor of compressive strength}

As shown in Fig. 5, a number of material laws exist in the literature for estimating the reduction factor of concrete compressive strength at elevated temperatures. It can be seen that there is a large variation from the different laws. For instance, the major difference between EC2 and ASCE is the effect of aggregate type on the compressive strength. In addition, the reduction factor of ASCE seems to be closer to the upper bound, and that of EC2 is closer to the lower bound [18]. According to the available models, one generic law is proposed here with neglecting the effect of aggregate type (see Table 2 and Fig. 5).

\subsection{Peak strain}

Fig. 6 presents the peak strains of concrete at elevated temperatures for different laws. Obviously, the laws of EC2 (2004) [17] and ASCE [19] provide the upper bound for the peak strain, and EC2 (1995) [34] provides the lower bound. It is evident that up to $500^{\circ} \mathrm{C}$, the peak strains given in EC2 (2004) and ASCE are close to each other and higher than those provided by the other laws. However, for higher values of temperature, there are clear differences in the peak strains between ASCE and EC2 laws. It should be mentioned here that in EC2 law, the peak strain includes the transient strain. Hence, as shown in Fig. 6, a general-purpose strain relationship is proposed for the peak strain as:

$$
\varepsilon_{p, T}=\left\{\begin{array}{cc}
2.5 \times 10^{-3}+8.8 \times 10^{-6} T+1.5 \times 10^{-8} T^{2} & T \leq 800^{\circ} \mathrm{C} \\
20 \times 10^{-3} & T>800^{\circ} \mathrm{C}
\end{array}\right.
$$

\subsection{Free thermal strain}

Fig. 7 shows the comparison of the free thermal-strain curves for the different laws. It is well known that the effect of aggregate type on the thermal strain is significant. However, only EC2 (2004) [17] distinguishes between the concrete types for thermal strain. On another hand, the difference gradually increases as temperature increases, particularly above $500^{\circ} \mathrm{C}$. For instance, at $700^{\circ} \mathrm{C}$, the thermal strain of Nechnech's law [36] is $7.88 \times 10^{-3}$, but that of EC2 law is $13.2 \times 10^{-3}$, the 
ratio is 1.68. Meanwhile, above $700{ }^{\circ} \mathrm{C}$, the value of the thermal expansion coefficient is a controversial issue. In fact, the previous experimental results indicate that in the temperature of 700 to $900{ }^{\circ} \mathrm{C}$, the free thermal strain does not increase [28]. But, ASCE and Nechnech [36] laws do not reflect this realistic property of concrete at elevated temperatures. Based on the comparisons, a generic thermal-strain law is proposed here, which is the modification of Nechnech's law. That is:

$$
\alpha= \begin{cases}10 \times 10^{-6} & T \leq 300^{\circ} \mathrm{C} \\ (0.025 T+2.5) \times 10^{-6} & 300^{\circ} \mathrm{C}<T \leq 900^{\circ} \mathrm{C} \\ 0.0 & T>900^{\circ} \mathrm{C}\end{cases}
$$

\subsection{Transient strain}

As reported in the literature, the transient strain of concrete is the strain that cannot otherwise be accounted for due to the decomposition of the cement paste. It occurs under compressive stress as temperature increases, and is essentially permanent, unrecoverable, and only occurs under initial heating. Also it is temperature-dependent and independent of time. The experimental results show that the transient strain is linearly proportional to the applied stress and nonlinearly increases with temperature [28].

For many researchers the transient strain law proposed by Anderberg and Thelandersson [28] has been adopted to calculate concrete transient strain. In this law the increment of concrete transient strain $\Delta \varepsilon_{\text {tr }}$ is related to the concrete thermal strain as:

$$
\Delta \varepsilon_{\mathrm{tr}}=\frac{\sigma}{f_{c, 20}} k_{\mathrm{tr}} \Delta \varepsilon_{\mathrm{th}}=\frac{\sigma}{f_{c, 20}} k_{\mathrm{tr}} \frac{\partial \varepsilon_{\mathrm{th}}}{\partial T} \Delta T
$$

where $k_{\mathrm{tr}}$ is a constant ranges between 1.8 and $2.35 ; \Delta \varepsilon_{\mathrm{th}}$ is the increment of concrete thermal strain; $\sigma$ is the compressive stress; $T$ is the temperature of concrete; $f_{\mathrm{c}, 20}$ is concrete strength at room temperature and $\varepsilon_{\mathrm{th}}$ is concrete thermal strain. $k_{\mathrm{tr}}\left(\partial \varepsilon_{\mathrm{th}} / \partial T\right)$ in Eq. (13) is defined as the transient strain function, which is related to $T$.

According to the existing laws [4, 37-39], the two simple transient strain relationships are proposed here to predict the upper and lower limits of the transient strain as:

$$
\Delta \varepsilon_{\text {tr,upper }}=\frac{\sigma}{f_{c, 20}}\left[2.08 \times 10^{-6}+5.66 \times 10^{-8} T+12.27 \times 10^{-11} T^{2}\right] \Delta \mathrm{T}
$$




$$
\Delta \varepsilon_{\text {tr,lower }}=\frac{\sigma}{f_{c, 20}}\left[9.59 \times 10^{-6}+5.5 \times 10^{-9} T+11.19 \times 10^{-11} T^{2}\right] \Delta \mathrm{T}
$$

According to Eq. (13), the concrete transient strain is influenced by using different thermal stain laws. Fig. 8 shows the comparison of the transient strain function $\left(k_{\mathrm{tr}}\left(\partial \varepsilon_{\mathrm{th}} / \partial T\right)\right)$ using different concrete thermal strain laws. It can be seen from Fig. 8 that the transient strain functions calculated by different concrete thermal strain laws exhibit a more limited dispersion when the temperature of concrete is less than $500{ }^{\circ} \mathrm{C}$. However, there are larger variations in the transient strain functions when the temperature of concrete is above $500{ }^{\circ} \mathrm{C}$. This is partly because fewer test data were reported for temperatures higher than $500^{\circ} \mathrm{C}$. Previous research indicates that there are two different points of view about the relationship between the transient strain and free thermal strain, particularly in the temperature range of 20 to $550^{\circ} \mathrm{C}$. For example, for Anderberg's model [28], the transient strain is proportional to the free thermal expansion, and thus the aggregate type has an important effect on this strain. However, according to the test results, Khoury et al. [40] reported that the transient strain is physically independent of the free thermal expansion. From the perspective of numerical analysis, it is reasonable to assume that the transient strain is proportional to the thermal strain, due to the same order of magnitude.

\subsection{Creep strain}

A review of the literature shows that the conventional creep strain is generally omitted in the structural analysis of RC members in fire. The main reason is that the creep strain plays a minor role compared to other strains. Hence, it is not considered in this paper.

For reinforcing steel, the total strain has three components, i.e., thermal strain, stress-related strain and creep strain. The instantaneous stress-related strain and thermal strain are evaluated according to EC2 law [17]. The creep strain is based on the Dorn-Harmthy relationship. The details of the steel material laws can be found in Ref. [30].

The concrete constitutive laws developed above have been incorporated into the computer program developed by the first author [30] for the structural analysis of RC slabs under fire conditions.

\subsection{Validations}

To validate the proposed transient laws two tests [28, 37] are used here. The details of these concrete specimens can be found from references [28] and [37].

\section{(a) Test one [37]}

Figs. 9(a) and 9(b) show the comparison among the transient strains predicted by the different laws 
against the test results for two stress levels. It is evident that the two specimens were first subjected to a uniaxial compressive stress and then heated at a constant rate. Clearly, the predictions of current laws agree reasonably well with the test data. For the two cases, the predictions of EC2 thermal strain law compare well with the test data, and the ASCE thermal strain law generally predicts the lower values of transient strain.

(b) Test two [28]

For this case, the concrete specimens were heated under two constant stress levels: $22.5 \%$ and $35.0 \%$ of the initial compressive strength $f_{c}$ [28]. The predictions of total strain by the different laws, together with the test results are shown in Fig. 10. It can be seen that the present laws reasonably predict the trend of the stress-related strain. In the temperature range of 20 to $600^{\circ} \mathrm{C}$, the predicted results of the current laws agree reasonably well with the test data. However, when the temperature > $700{ }^{\circ} \mathrm{C}$, the stress-related strains are underestimated by the present laws. Similar predictions were provided by ASCE and EC2. It is obvious that the predictions by the present upper law agree better with the measured results.

\section{Modelling the RC slabs fire tests}

In this section, 3 full-scale slabs [31-32] and 10 small-scale slabs [33] tested in fire were modelled using the thermal model and concrete material laws developed in this paper. As mentioned above, the predicted temperatures of the slabs were used as the temperature inputs for the structural analysis.

Figs. 11 and 12 show the comparisons between the tested central deflections and the current model's predictions for the full-scale slabs [31, 32]. Figs. 13 to 15 show the comparisons between the tested central deflections and the current model's predictions for the small-scale slabs [33].

Table 3 gives the quantitive comparisons between the predicted and tested results in terms of the mid-span deflection $\delta$ and fire resistance time $t$. Also the ratio of predicted $(\delta, t)$ and tested $\left(\delta_{\text {exp }}, t_{\text {exp }}\right)$ were calculated separately for each slab. Clearly, the mean values of $t / t_{\exp }$ and $\delta / \delta_{\exp }$ are 0.88 and 1.04 with the standard deviation of 0.09 for the full-scale slabs [31, 32]. However, the mean values of $t / t_{\exp }$ and $\delta / \delta_{\exp }$ are 0.83 and 0.5 with the standard deviation of 0.26 for the small-scale slabs [33]. It is evident that the considerable differences between the predicted and tested results for the small-scale slabs [33] are partly due to the inaccurate predictions of the temperatures within the small-scale slabs. Only one slab's test temperatures were reported in Ref. [33]. However, in comparison with the test results, the predictions generated by current models are on the conservative side. Therefore, the current models can be used for the fire resistance design of RC 
slabs.

\section{Parametric studies}

In this section, a series of parametric studies on the behaviour of RC slabs under fire conditions are presented, including the moisture content $\left(m_{w}\right)$, transient strain, different constitutive models and size effect. In this study, spalling of the slabs was not taken into account for simplicity.

\subsection{Effect of moisture content $\left(m_{\mathrm{w}}\right)$}

In the paper, for the thermal analysis, a parameter $m_{\mathrm{w}}$ was introduced to take into account the non-uniform distribution of moisture content along the thickness of slabs due to the influence of moisture clog. It is assumed that the moisture content along the thickness of concrete slab is a simple function of the temperature. However, the distribution of moisture content along the thickness of slabs with time is extremely difficult to measure experimentally with a good degree of accuracy [1-2], and thus the test data is relatively rare. Therefore how to determinate the value of $m_{\mathrm{w}}$ for the slab with different thicknesses is not an easy task. In all, the present method is mainly applicable for the slabs with similar thickness and heating rates to these discussed in the paper. For other cases, the corresponding tests and numerical analysis are needed.

Hence, in this section the influence of $m_{\mathrm{w}}$ is assessed by modelling of the full-scale slabs (D147, 661 and 4ES-2). Four values of $m_{w}=0 ; 1.0,2.0,3.0$.were used and the results are shown in Figs.16 and 17 which indicate the impact of $m_{w}$ on the thermal and structural behaviours of slabs under fire conditions.

As shown in Fig.16, the moisture content has a considerable influence on the temperature histories of the full-scale slab, in which the predicted temperatures decrease as the moisture content increases. With the increase of the distance from the fire exposed surface, the influence of the moisture content becomes more and more significant on the temperature development within the cooler part of the slab. Take Slab D147 as an example, after 100 min fire exposure, the predicted temperature at the fire exposed surface decreased from $964^{\circ} \mathrm{C}$ to $954^{\circ} \mathrm{C}$, when $m_{w}$ increased from 0 to 3 , while the corresponding temperature at $95 \mathrm{~mm}$ (away from the fire exposed surface ) decreased from $241^{\circ} \mathrm{C}$ to $121^{\circ} \mathrm{C}$. In addition, as $m_{\mathrm{w}}$ increased from 0 to 3 , the duration of the temperature plateau of Slab D147 (at 95mm) increased from 0 to $35 \mathrm{~min}$.

As shown in Fig. 17, the influence of moisture contents on the predicted deflection is considerably significant in the full-scale slabs. This is due to the impact of moisture content on the temperature predictions of the slab. For example, as $m_{w}$ increased from 0 to 3.0, the fire resistance of the Slab 
D147 increased from 131 to 155 min (increase ratio $=16.5 \%$ ), Similarly, the increased ratios of the Slabs 661 (from 138 to $148 \mathrm{~min}$ ) and 4ES-2 (from 185 to $213 \mathrm{~min}$ ) are $7.3 \%$ and $15.1 \%$, respectively.

\subsection{Effect of the transient strain}

To investigate the effect of the transient strain on the structural behaviour of RC slabs, one full-scale slab (Slab D147 [31]) and one small-scale slab (Slab MF3 [33]) were modelled. For each slab, three analyses were conducted: (1) neglecting the transient strain, (2) a transient strain modelled using the current lower bound law, and (3) a transient strain modelled using the current upper bound law.

Figs. 18(a) and 18(b) show the mid-span deflections against test time, for the three analyses. It is evident that the transient strain has a limited influence on the structural behaviour of RC slabs under fire conditions. This is because the slabs are mainly subjected to bending, and the compressive stresses are mainly distributed within the cooler top part of the slabs. As reported in reference [4], the effect of transient strain on the behaviour of the simply supported RC beam can be neglected in the numerical analysis.

\subsection{Effect of concrete material laws}

To investigate the influence of different concrete thermal laws on the predictions of temperatures within the RC-slabs, a full-scale Slab D147 [31] and a small-scale slab [33] were modelled using EC2, ASCE and present thermal laws. The results are shown in Figs. 19(a) and 19(b).

As shown in Fig. 19(a), the predicted temperatures on the exposed surface are almost identical for the three different laws. However, at other points, there is a considerable deviation between the three predictions. In addition, at the positions close to the unexposed surface, EC2 and ASCE laws cannot predict the temperature plateau (about $100^{\circ} \mathrm{C}$ ). As shown in Fig. 19(b), in this case there is a little discrepancy between the three predictions. This is because the thickness of the slab is small. Overall, the current model gives reasonable predictions.

The comparative analysis shows that since EC2 and ASCE thermal models do not consider the moisture clog within the cooler part of the cross-section of structural members, their models cannot reasonably predict the temperature plateau, particularly for the thick slabs. However, according to the test results there was no clear temperature plateau existed within the cross-section of thin slab. Hence, the moisture clog can be neglected in this case. The moisture clog reflects the size effect of slabs. It is clear that as the slab's thickness increased the influence of the moisture clog effect become more significant. 
For EC2 model, it is assumed that the initial moisture content is uniformly distributed along the cross-section of structural members. Therefore the initial moisture content is considered by increasing specific heat of concrete [17]. However, in the current developed model it is assumed that the moisture content is non-uniformly distributed along the cross-section of slabs due to the influence of moisture clog which leads to larger moisture content values (such as 2 or 3 times the initial moisture content) at the temperature between $100^{\circ} \mathrm{C}$ and $300^{\circ} \mathrm{C}$. Similarly, for the ASCE model [18-19], the effect of moisture content on the heat capacity of concrete is not considered.

For assessing the influence of the different concrete constitutive laws on the predictions of structural behaviour, the previously-mentioned concrete slabs (D147 [31] and MF9 [33]) were modelled using EC2, ASCE, and the concrete constitutive laws developed in this paper. The comparison of the predicted mid-span deflections of the RC-slabs using the different constitutive laws is shown in Figs. 20(a) and 20(b). It can be seen that the predictions of different models have considerable variations. It is evident that ASCE law generally underestimates the mid-span deflection of the slabs and predicts high fire resistance time. The predictions of the current model are relatively closed to the results of EC2 law. Overall, compared to the test results the current model is able to give reasonable predictions and conservative fire resistance (Table 3).

The analysis indicates that compared to the experimental results, the deflections of the concrete slabs predicted based on EC2 or ASCE models may be overestimated or underestimated. This observation is similar to the results discussed in Ref. [18]. One main reason is that compared to the experimental data, the compressive strength reduction factor proposed in ASCE model seems to be closed to the upper bound, and EC2 model is closed to the lower bound. In addition, compared to EC2 and ASCE models, the major difference is how to consider the effect of aggregate type. As discussed above, EC2 model does not account for the effect of aggregate type on the thermal capacity but considers its effect on the compressive strength and thermal strain. In contrast, ASCE model accounts for the effect of aggregate type on the thermal capacity and thermal conductivity but does not consider its effect on the compressive strength and thermal strain.

\subsection{Effect of finite element size}

The influence of mesh size $(3 \times 4$ and $6 \times 8)$ on the structural response of the RC slabs in fire were investigated, as shown in Figs. 21(a) and 21(b). Clearly, a mesh of 3 elements for the short span and 4 elements for the long span can generate reasonable predictions for Slabs D147 and M9. In other words, the deflection of the slabs was found to be non-sensitive to the mesh size. This observation is similar to the numerical results in Reference [41].

Figs. 22(a) and 22(b) show the distributions and orientations of the two principal membrane 
tractions at the Gauss points of Slab M9 (different meshes). The compressive and tensile membrane tractions are plotted as thick and thin lines, respectively. The lengths of the lines indicate the magnitude of the membrane tractions. Clearly, the similar membrane distributions further verifies the efficiency of the present model.

\section{Conclusions}

In this paper a numerical procedure for thermal analysis of RC slabs at elevated temperatures has been proposed. In this model the moisture increase due to the moisture clog within the cooler part of the cross-section of a RC member is considered. Based on a systematic investigation of the existing concrete constitutive laws available from current design codes and literature, the concrete constitutive laws at elevated temperatures are proposed. The proposed thermal and constitutive laws of concrete are compared with the laws of the current design codes and the laws proposed in the previous literature. The new models are also validated against the well-documented full-scale and small-scale fire tests on simply supported RC slabs. A series of parametric studies on the behaviour of RC slabs under fire conditions are conducted to investigate the effect of moisture content, transient strain, different concrete material laws and size effect on the analyses of the RC slabs under fire conditions. Based on the results generated in this research the following conclusions can be drawn:

- The thermal analysis model developed in this paper can be used to predict the temperatures of RC slabs under fire conditions. The moisture content within the RC slabs has a considerable influence on the temperature distributions of the slabs in fire. The structural behaviour of the slabs is also affected by the moisture content of the concrete. Hence, the moisture content of RC slabs needs to be accurately accounted for in calculating the fire resistance of RC slabs.

- There are considerable variations of the predicted temperatures for RC slabs in using the existing concrete thermal models. The EC2 [11] and ASCE [13] laws cannot predict the temperature plateau (about $100^{\circ} \mathrm{C}$ ) within RC slabs.

- The concrete constitutive laws proposed in this paper are able to predict the fire resistance times of the slabs with good accuracy. Compared to the test results the predictions are on the safe side. Hence, it can be argued that the proposed concrete constitutive laws can be used for the fire resistance design of RC slabs.

- As slabs are mainly subjected to bending, the compressive stresses are mostly distributed in the top fibers, which are the coolest part of the slab. Consequently, in the simply-supported 
$\mathrm{RC}$ slabs, the effect of concrete transient strains is negligible.

- The results obtained from the parametric studies show that the predictions by different concrete constitutive laws have considerable variations. It is evident that the ASCE [13] laws generally underestimates the mid-span deflection of the slabs and predicts high fire resistance time.

\section{Acknowledgements}

This research was supported by the Fundamental Research Funds for the Central Universities (Grant No.2018QNB10). The authors gratefully acknowledge the support.

\section{References}

[1] Huang Z., Burgess I.W., Plank R.J., Modeling membrane action of concrete slabs in composite buildings in fire. I: Theoretical development, J Struct Eng, 2003, 129: 1093-1102.

[2] Huang Z., Burgess I.W., Plank R.J., Modeling membrane action of concrete slabs in composite buildings in fire. II: Validations, J Struct Eng, 2003, 129: 1103-1112.

[3] Lim L., Buchanan A., Moss P., Franssen J.M., Numerical modelling of two-way reinforced concrete slabs in fire, Eng Struct, 2004, 26: 1081-1091.

[4] Lu L. M., Yuan Y., Caspeele R., Taerwe L., Influencing factors for fire performance of simply supported RC beams with implicit and explicit transient creep strain material models, Fire Safety Jornal, 2015, 73: 29-36.

[5] Liao F., Huang Z., An extended finite element model for modelling localised fracture of reinforced concrete beams in fire, Comput Struct, 2015, 152: 11-26.

[6] Hurst J.P., Ahmed G.N., Validation and application of a computer model for predicting the thermal response of concrete slabs subjected to fire, ACI Struct J, 1998, 95: 480-487.

[7] Tenchev R.T., Li L.Y., Purkiss J.A., Finite element analysis of coupled heat and moisture transfer in concrete subjected to fire, Num Heat Transfer A: Appl, 2001, 39: 685-710.

[8] Gawin D., Pesavento F., Schrefler B.A. Modelling of hygro-thermal behaviour of concrete at high temperature with thermo-chemical and mechanical material degradation. Comput. Methods Appl. Mech. Engrg, 2003, 192:1731-1771.

[9] M B Dwaikat, V K R Kodur. Hydrothermal model for predicting fire-induced spalling in concrete structural systems. Fire Safety Journal, 2009, 44: 425-434. 
[10] Wickstro“ m UA. Computer program for temperature analysis of structures exposed to fire. Report no 79-2. Lund Sweden: Lund Institute of Technology; 1979.

[11] Huang Z., Platten A., Roberts J., Non-linear finite element model to predict temperature histories within reinforced concrete in fires, Build Environ, 1996, 31: 109-118.

[12] Lamont S., Usmani A.S., Drysdale D. D. Heat transfer analysis of the composite slab in the Cardington frame fire tests, Fire Safety Journal, 2001, 36: 815-839.

[13] V K R Kodur, Luke A Bisby. Evaluation of fire endurance of concrete slabs reinforced with Fiber-reinforced polymer bars. Journal of Structural Engineering, 2005, 131 (1): 34-43.

[14] L A Bisby, V K R Kodur. Evaluating the fire endurance of concrete slabs reinforced with FRP bars: considerations for a holistic approach. Composites: Part B, 2007, 38: 547-558.

[15] Capua D.D., Mari A.R., Nonlinear analysis of reinforced concrete cross-sections exposed to fire, Fire Safety Journal, 2007, 42: 139-149.

[16] Binsheng Zhang, Effects of moisture evaporation (weight loss) on fracture properties of high performance concrete subjected to high temperatures. Fire Safety Journal, 2011, 46: 543-549.

[17] Eurocode 2: Design of concrete structures, ENV 1992: Part 1-2: General rules-Structural fire design, Belgian Application Document, Brussels, 2004.

[18] Kodur V.K., Dwaikat M., High-temperature properties of concrete for fire resistance modeling of structures, ACI Mater J, 2008, 105.

[19] ASCE: Structural Fire Protection, Manual No. 78, ASCE Committee on Fire Protection, Structural Division, American Society of Civil Engineers, New York, 1992.

[20] Li L.Y., Purkiss J., Stress-strain constitutive equations of concrete material at elevated temperatures, Fire Safety J, 2005, 40: 669-686.

[21] Youssef M.A., Moftah M., General stress-strain relationship for concrete at elevated temperatures, Eng Struct, 2007, 29: 2618-2634.

[22] Law A., Gillie M., Load induced thermal strain:implications for structural behavior, SIF 2008, Proceedings of the fifth international conference-structures in fire, Singapore, 2008, pp. 488-496.

[23] Gernay T., Franssen J.M., A formulation of the Eurocode 2 concrete model at elevated temperature that includes an explicit term for transient creep, Fire Safety J, 2012, 51: 1-9.

[24] Thomas Gernay, Alain Millard, Jean-Marc Franssen. A multiaxial constitutive model for concrete in the fire situation: theoretical formulation. International Journal of Solids and Structures, 
[25] Giacomo Torelli, Parthasarathi Mandal, Martin Gillie, Van-Xuan Tran. Concrete strains under transient thermal conditions: A state-of-the-art review. Engineering Structures, 2016: 127: 172-188.

[26] Giacomo Torelli, Martin Gillie, Parthasarathi Mandal, Van-Xuan Tran. A multiaxial load-induced thermal strain constitutive model for concrete. International Journal of Solids and Structures, 2017, 108: 115-125.

[27] Bamonte P. and Lo Monte F. "Reinforced concrete columns exposed to standard fire: Comparison among different constitutive models for concrete at high temperature", Fire Safety Journal, 2015, 71: 310-323.

[28] Anderberg Y., Thelandersson S., Stress and deformation characteristics of concrete at elevated temperatures Part II: Experimental investigation and material behaviour model, Bulletin, 1976.

[29] Ang C., Wang Y., The effect of water movement on specific heat of gypsum plasterboard in heat transfer analysis under natural fire exposure, Constr Build Mater, 2004, 18: 505-515.

[30] Wang Y., Dong Y.L., Zhou G.C., Nonlinear numerical modeling of two-way reinforced concrete slabs subjected to fire, Comput Struct, 2013, 119: 23-36.

[31] Lim L., Wade C., Experimental fire tests of two-way concrete slabs, Research Report, School of Engineering, University of Canterbury, 2002.

[32] Wang B., Dong Y.L., Experimental research of four-edge simple support two-way reinforced concrete slab under fire, J Build Struct, 2009, 30: 23-33.

[33] Bailey C.G., Toh W.S., Small-scale concrete slab tests at ambient and elevated temperatures, Eng Struct, 2007, 29: 2775-2791.

[34] Eurocode 2: Design of concrete structures, ENV 1992: Part 1-2: General rules-Structural fire design, Belgian Application Document, Brussels, 1995.

[35] Guo Z.H, Shi X.D., Experimental and calculation of reinforced concrete at elevated temperatures, Tsinghua Universing Press, Beijing, 2003.

[36] Nechnech W., Meftah F., Reynouard J.M., An elasto-plastic damage model for plain concrete subjected to high temperatures, Eng Struct, 2002, 24: 597-611.

[37] Persson B., Self-compacting concrete at fire temperature. TVBM-3110.Sweden (Lund): Division of building materials, Lund Insitute of Technology, 2003.

[38] Youssef M.A., Moftah M., General stress-strain relationship for concrete at elevated 
temperatures, Eng Struct, 2007, 29: 2618-2634.

[39] Nielsen C.V, Pearce C.J., Bicanic N., Theoretical model of high temperature effects on uniaxial concrete member under elastic restraint, Mag. Concr. Res, 2002, 54: 239-249.

[40] Khoury G.A., Grainger B.N., Transient thermal strain of concrete:literature review, conditions within specimen and behavior of individual constituents, Mag. Concr. Res, 1985, 37: 131-144.

[41] Jian Jiang, Guo-Qiang Li. Parameters affecting tensile membrane action of reinforced concrete floors subjected to elevated temperatures. Fire Safety Journal, 2018, 96: 59-73. 
Tables

Table 1 Details of tested RC slabs.

\begin{tabular}{|c|c|c|c|c|c|c|c|c|c|c|c|c|c|c|c|}
\hline \multicolumn{2}{|c|}{ Property } & D147 & 661 & \multicolumn{2}{|c|}{ 4ES-2 } & MF1 & MF2 & MF3 & MF4 & MF5 & MF6 & MF7 & MF8 & MF9 & MF10 \\
\hline \multicolumn{2}{|c|}{ Length (mm) } & 4300 & 4300 & \multicolumn{2}{|c|}{6000} & 1700 & 1100 & 1700 & 1100 & 1700 & 1100 & 1700 & 1100 & 1700 & 1100 \\
\hline \multicolumn{2}{|c|}{ Width (mm) } & 3300 & 3300 & \multicolumn{2}{|c|}{4500} & 1100 & 1100 & 1100 & 1100 & 1100 & 1100 & 1100 & 1100 & 1100 & 1100 \\
\hline \multicolumn{2}{|c|}{ Thickness (mm) } & 100 & 100 & \multicolumn{2}{|c|}{120} & 19.7 & 23.1 & 19.0 & 19.8 & 20.1 & 19.5 & 18.8 & 20.9 & 21.6 & 21 \\
\hline \multicolumn{2}{|c|}{ Applied load $\left(\mathrm{kN} / \mathrm{m}^{2}\right)$} & 3.0 & 3.0 & \multicolumn{2}{|c|}{2.0} & 5.28 & 5.52 & 3.66 & 5.43 & 5.28 & 7.90 & 4.46 & 4.65 & 3.70 & 5.49 \\
\hline \multirow{2}{*}{ Concrete } & $\begin{array}{l}\text { Compressive } \\
\text { strength (MPa) }\end{array}$ & 37.0 & 37.0 & \multicolumn{2}{|c|}{32.0} & 43.2 & 43.3 & 39.1 & 39.0 & 37.1 & 38.5 & 43.8 & 43.5 & 47.1 & 40.4 \\
\hline & $\begin{array}{l}\text { Cover thickness } \\
\qquad(\mathrm{mm})\end{array}$ & 25 & 25 & \multicolumn{2}{|c|}{15} & \multicolumn{10}{|c|}{5} \\
\hline \multirow{4}{*}{$\begin{array}{c}\text { Reinforcing } \\
\text { steel }\end{array}$} & Diameter (mm) & 8.7 & 7.5 & \multicolumn{2}{|c|}{8.0} & 2.43 & 2.41 & 1.54 & 1.54 & 1.51 & 1.51 & 0.85 & 0.85 & 0.71 & 0.71 \\
\hline & \multirow{2}{*}{$\begin{array}{l}\text { Steel content } \\
\left(\mathrm{mm}^{2} / \mathrm{m}\right)\end{array}$} & \multirow{2}{*}{198} & \multirow{2}{*}{295} & $L^{*}$ & $W^{*}$ & \multirow{2}{*}{91.3} & \multirow{2}{*}{90} & \multirow{2}{*}{73.4} & \multirow{2}{*}{73.4} & \multirow{2}{*}{141} & \multirow{2}{*}{141} & \multirow{2}{*}{44.7} & \multirow{2}{*}{44.7} & \multirow{2}{*}{62.4} & \multirow{2}{*}{62.4} \\
\hline & & & & 280 & 250 & & & & & & & & & & \\
\hline & $\begin{array}{l}\text { Yield strength } \\
(\mathrm{MPa})\end{array}$ & 565 & 568 & \multicolumn{2}{|c|}{435} & 709 & 732 & 343 & 343 & 435 & 435 & 438 & 438 & 410 & 410 \\
\hline
\end{tabular}

$L^{*}$ : long span direction; $W^{*}$ : short span direction

Table 2 Proposed reduction factor of concrete compressive strength at elevated temperatures.

\begin{tabular}{|c|c|c|c|c|c|c|c|c|c|c|c|c|c|}
\hline$T\left({ }^{\circ} \mathrm{C}\right)$ & 20 & 100 & 200 & 300 & 400 & 500 & 600 & 700 & 800 & 900 & 1000 & 1100 & 1200 \\
\hline$f_{c, T} / f_{c, 20}$ & 1.0 & 0.98 & 0.96 & 0.92 & 0.84 & 0.70 & 0.53 & 0.35 & 0.20 & 0.09 & 0.04 & 0.016 & 0 \\
\hline
\end{tabular}

Table 3 Predicted and tested mid-span deflections and fire resistance times for the slabs.

\begin{tabular}{|c|c|c|c|c|c|c|c|c|c|c|c|c|c|c|}
\hline \multicolumn{2}{|c|}{ Slab } & D147 & 661 & 4ES-2 & MF1 & MF2 & MF3 & MF4 & MF5 & MF6 & MF7 & MF8 & MF9 & MF10 \\
\hline \multirow{2}{*}{ Tested } & $t_{\exp }(\min )$ & 180 & 180 & 192 & 166.6 & 181.5 & 176.5 & 166.6 & 176.5 & 190 & 135 & 157.0 & 157 & 162 \\
\hline & $\delta_{\exp }(\mathrm{mm})$ & 271 & 208 & 257 & -197.2 & -161.6 & -200 & -147 & -200 & -170 & -160 & -117.0 & -160 & -110 \\
\hline \multirow{2}{*}{ Predicted } & $t(\min )$ & 144 & 146 & 202 & 149.4 & 143.7 & 145.2 & 139.8 & 152.1 & 138.9 & 125.1 & 115.1 & 132.6 & 137.5 \\
\hline & $\delta(\mathrm{mm})$ & 231 & 254 & 272 & -89.7 & -70.2 & -87.8 & -71.3 & -91.1 & -69.5 & -77.4 & -71.8 & -85.9 & -74.0 \\
\hline \multirow{2}{*}{$\begin{array}{c}\text { Predicted/ } \\
\text { Tested }\end{array}$} & $t / t_{\exp }$ & 0.80 & 0.80 & 1.05 & 0.90 & 0.79 & 0.82 & 0.84 & 0.86 & 0.73 & 0.93 & 0.73 & 0.85 & 0.85 \\
\hline & $\delta / \delta_{\exp }$ & 0.85 & 1.22 & 1.06 & 0.46 & 0.43 & 0.44 & 0.49 & 0.46 & 0.41 & 0.48 & 0.61 & 0.54 & 0.67 \\
\hline
\end{tabular}




\section{Figures}

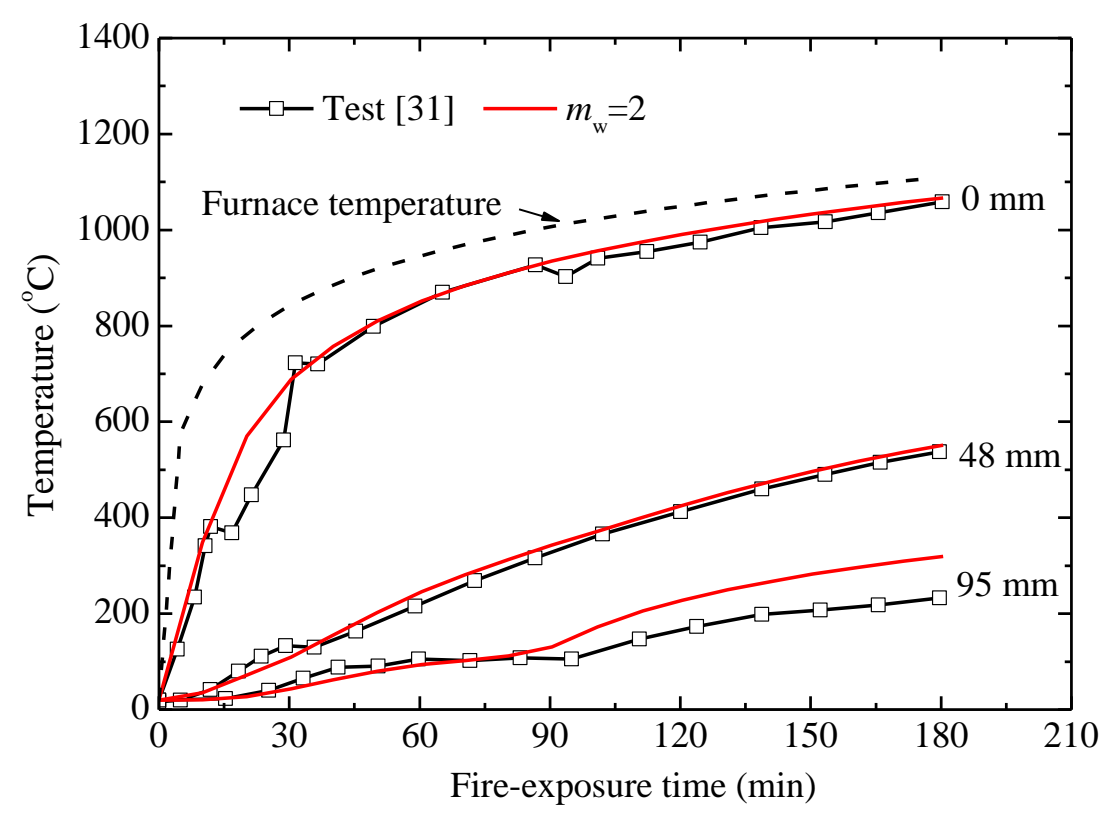

(a) Slab D147

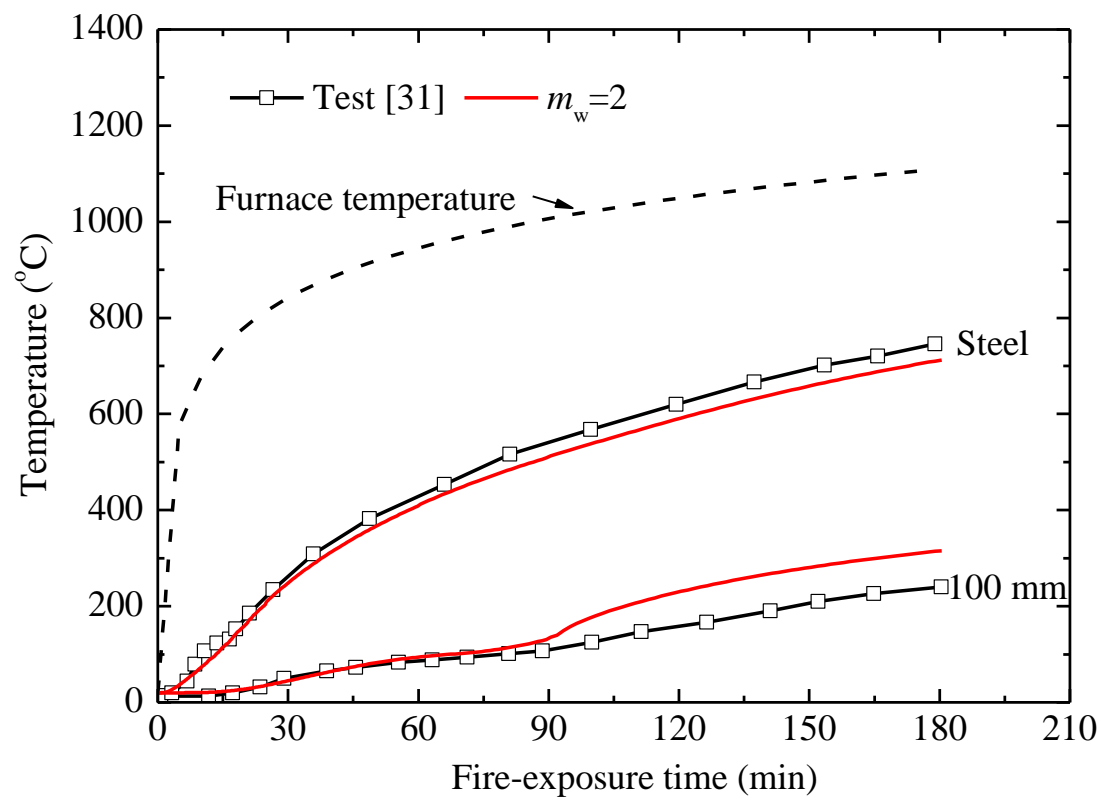

(b) Slab 661

Fig. 1 The effect of the moisture content on the temperature distributions of the slabs [31]. 


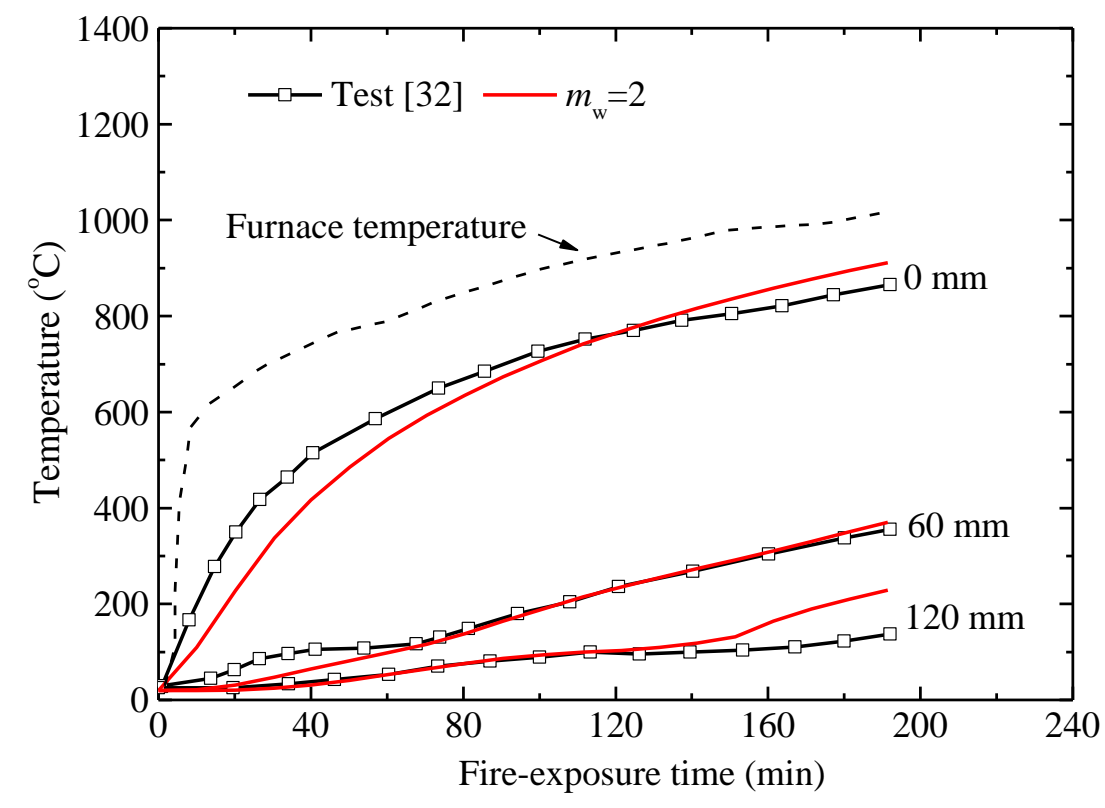

Fig. 2 The effect of the moisture content on the temperature distributions of the Slab 4ES-2 [32].

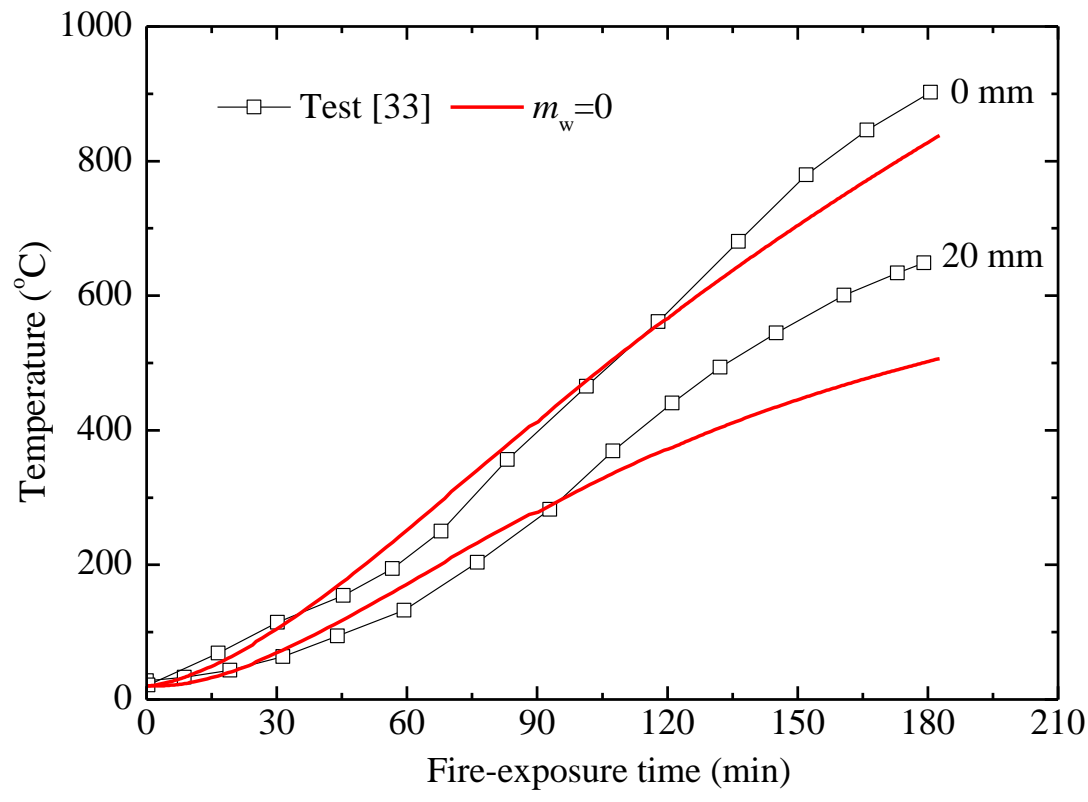

Fig. 3 The effect of the moisture content on the temperature distributions of the small-scale slab [33]. 


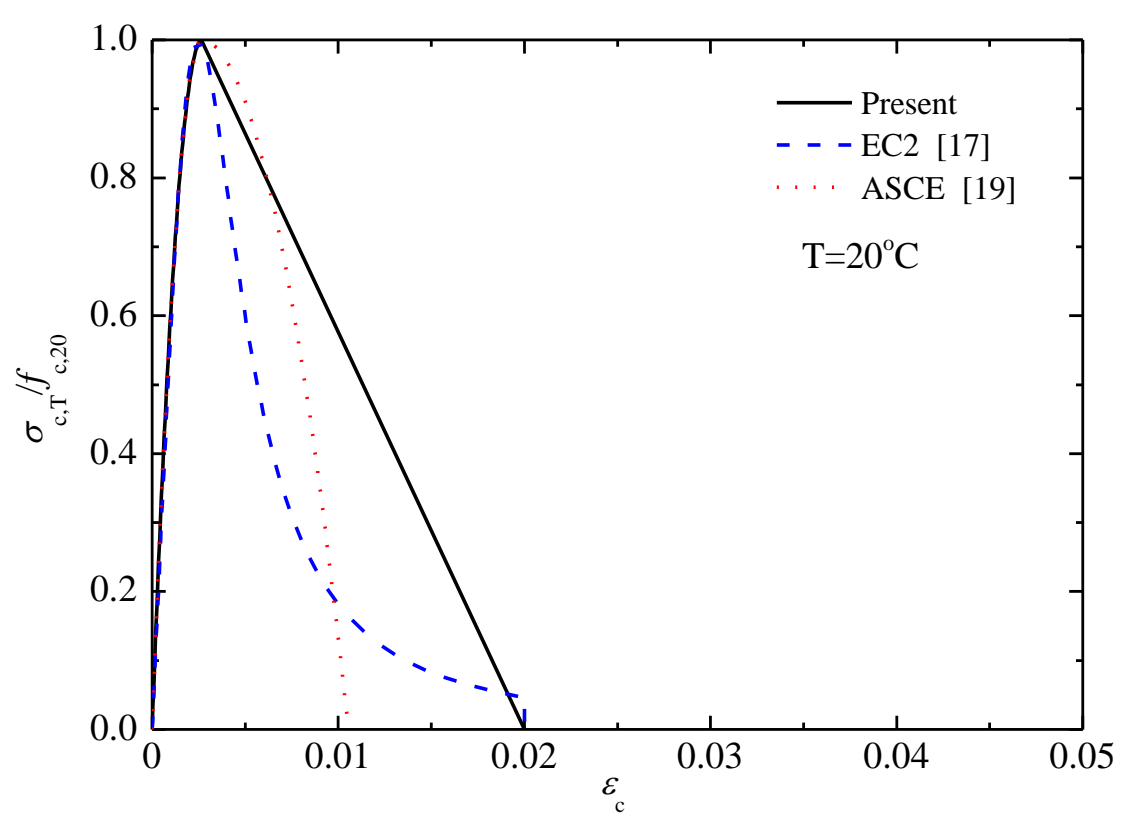

(a) $20^{\circ} \mathrm{C}$

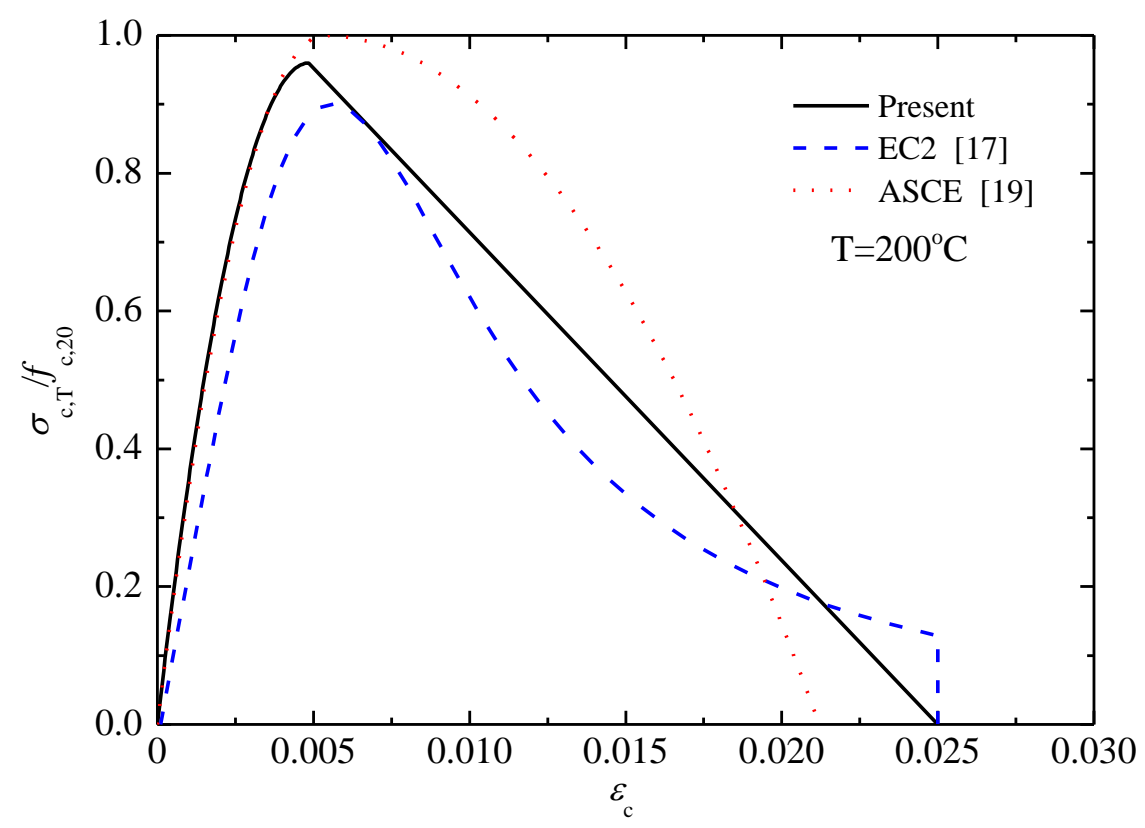

(b) $200{ }^{\circ} \mathrm{C}$ 


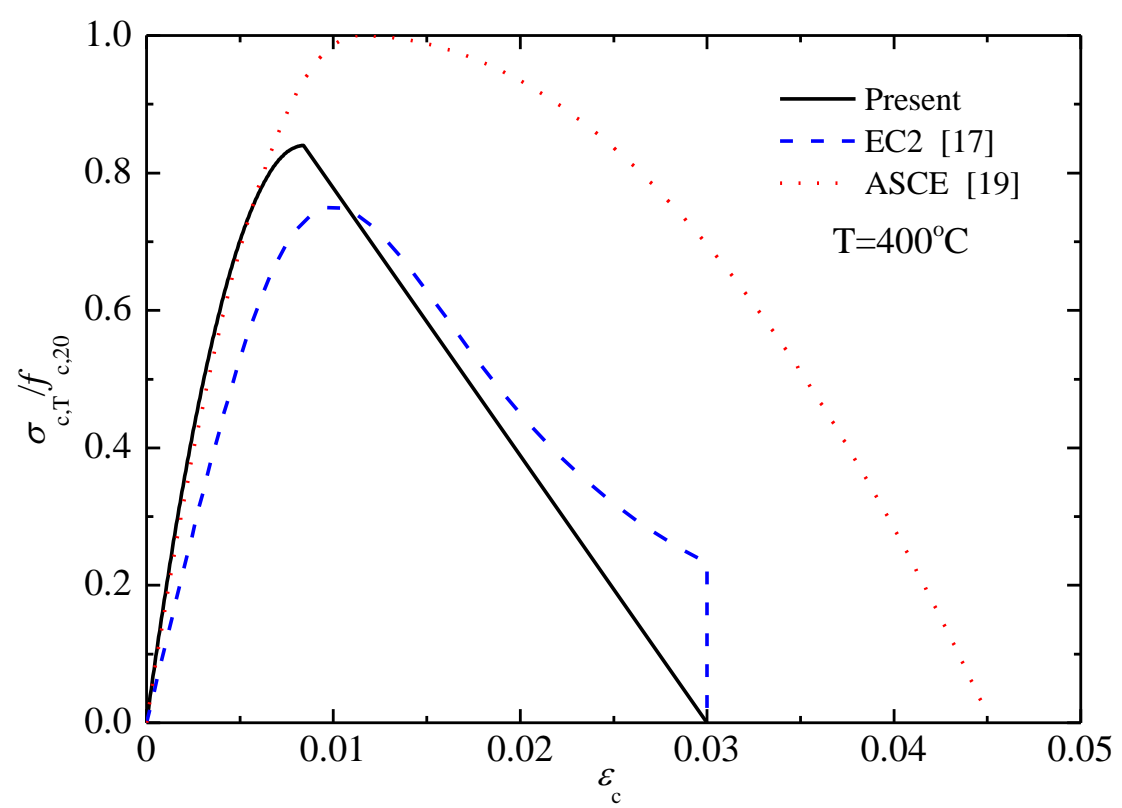

(b) $400{ }^{\circ} \mathrm{C}$

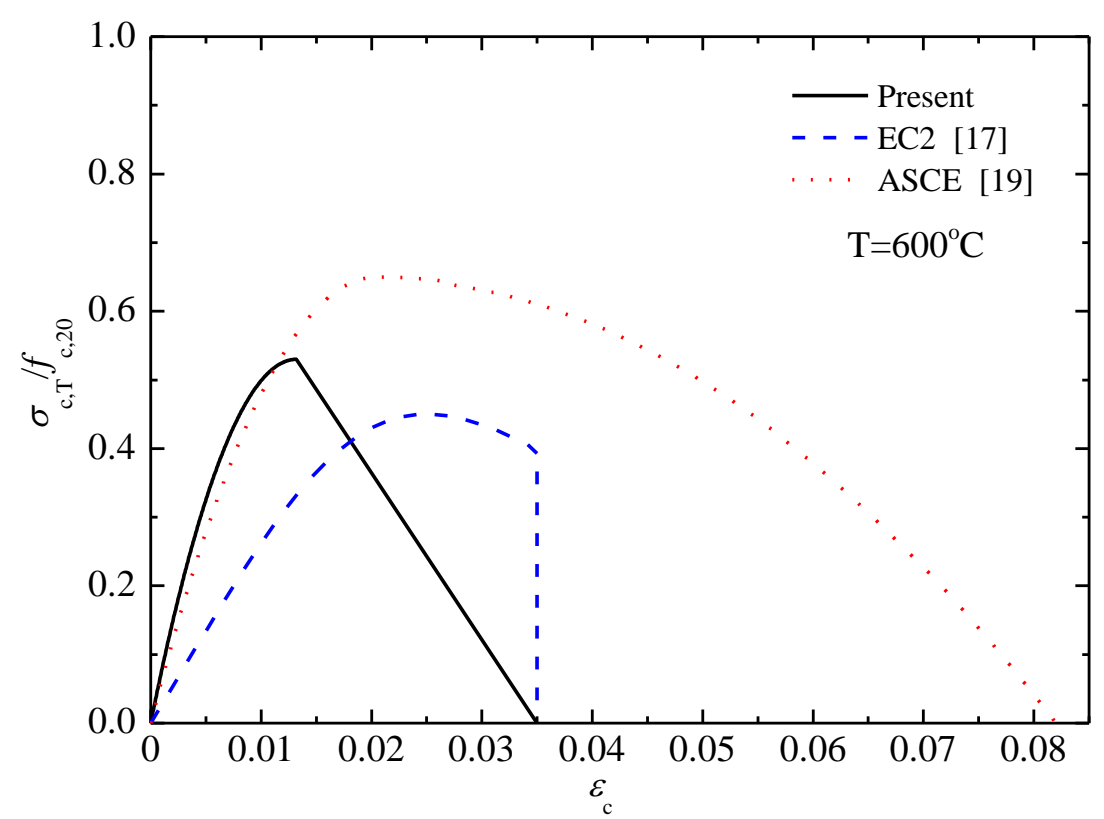

(d) $600{ }^{\circ} \mathrm{C}$ 


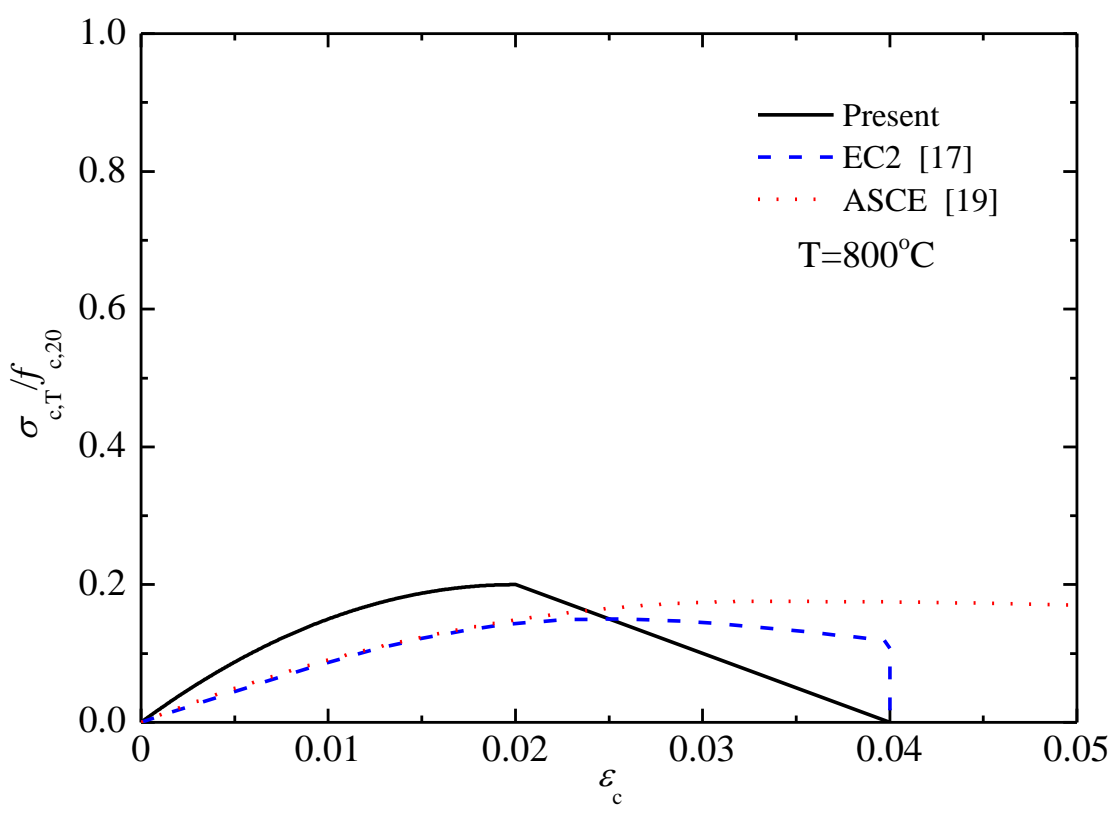

(e) $800^{\circ} \mathrm{C}$

Fig. 4 Comparison of the stress-strain relations of three concrete material laws at different temperatures.

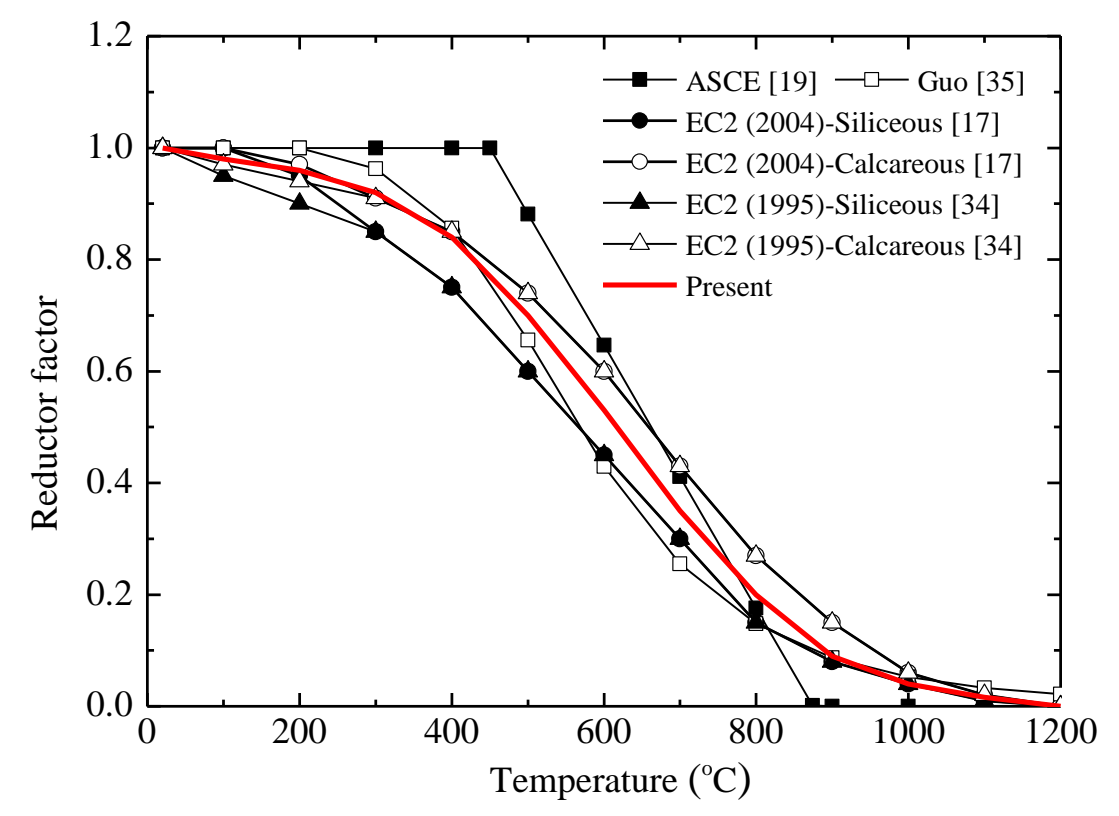

Fig. 5 The reduction factors of concrete compressive strength at elevated temperatures for different laws. 


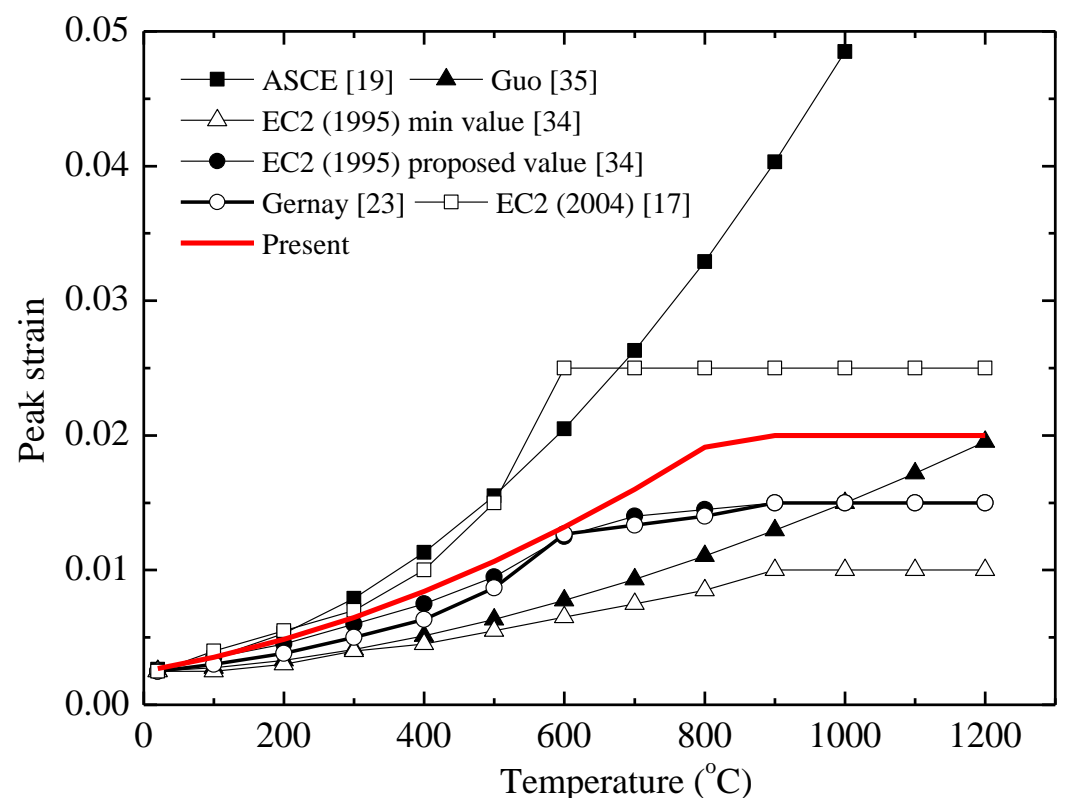

Fig. 6 The peak strains of concrete at elevated temperatures for different laws.

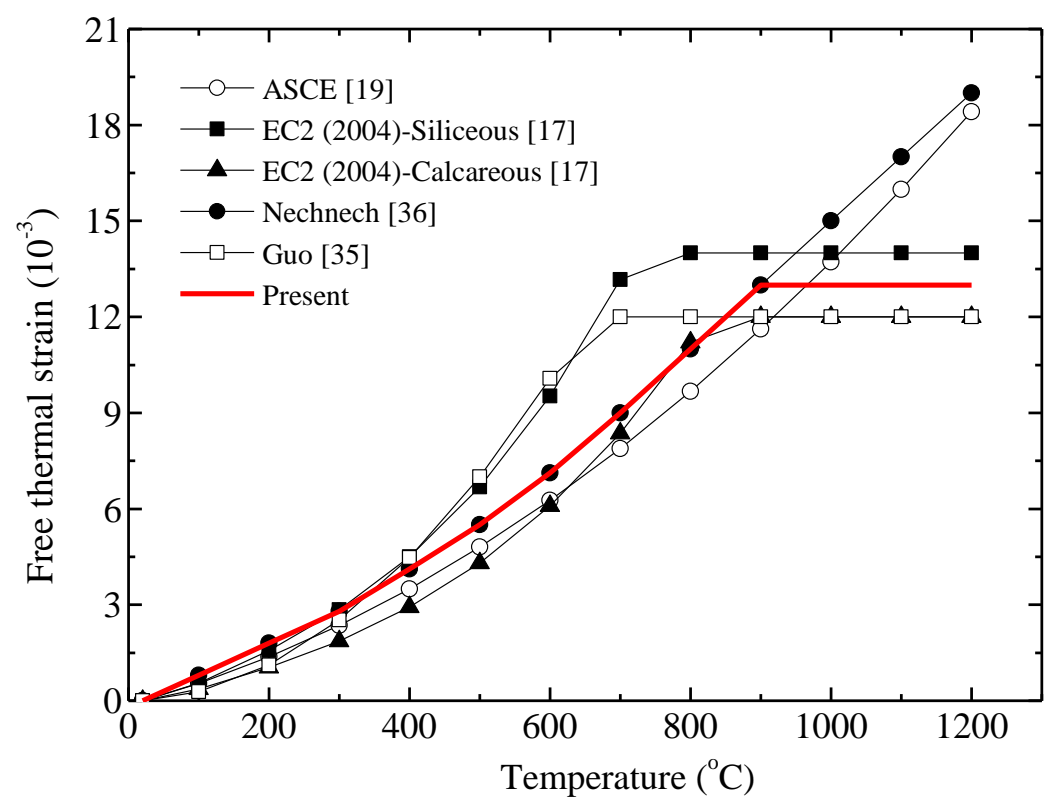

Fig. 7 Comparison of the free thermal-strain curves for the different laws. 


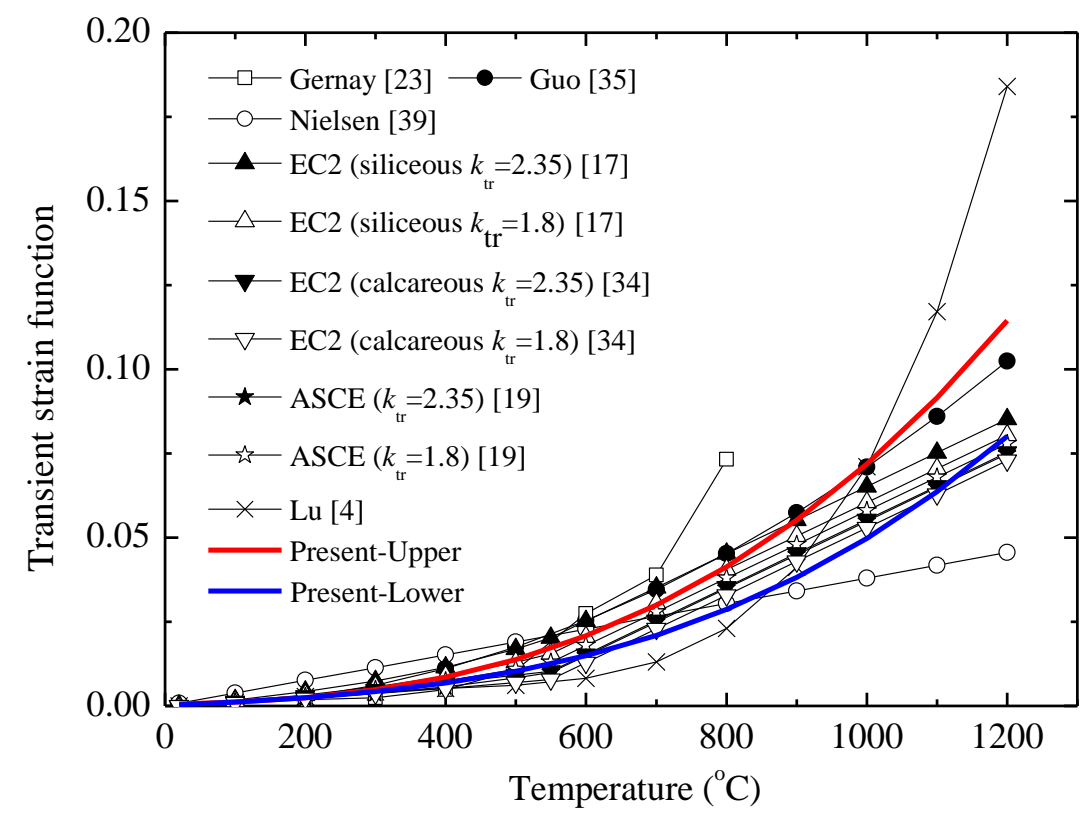

Fig. 8 Comparison of the different transient strain functions with different laws of concrete thermal strain.

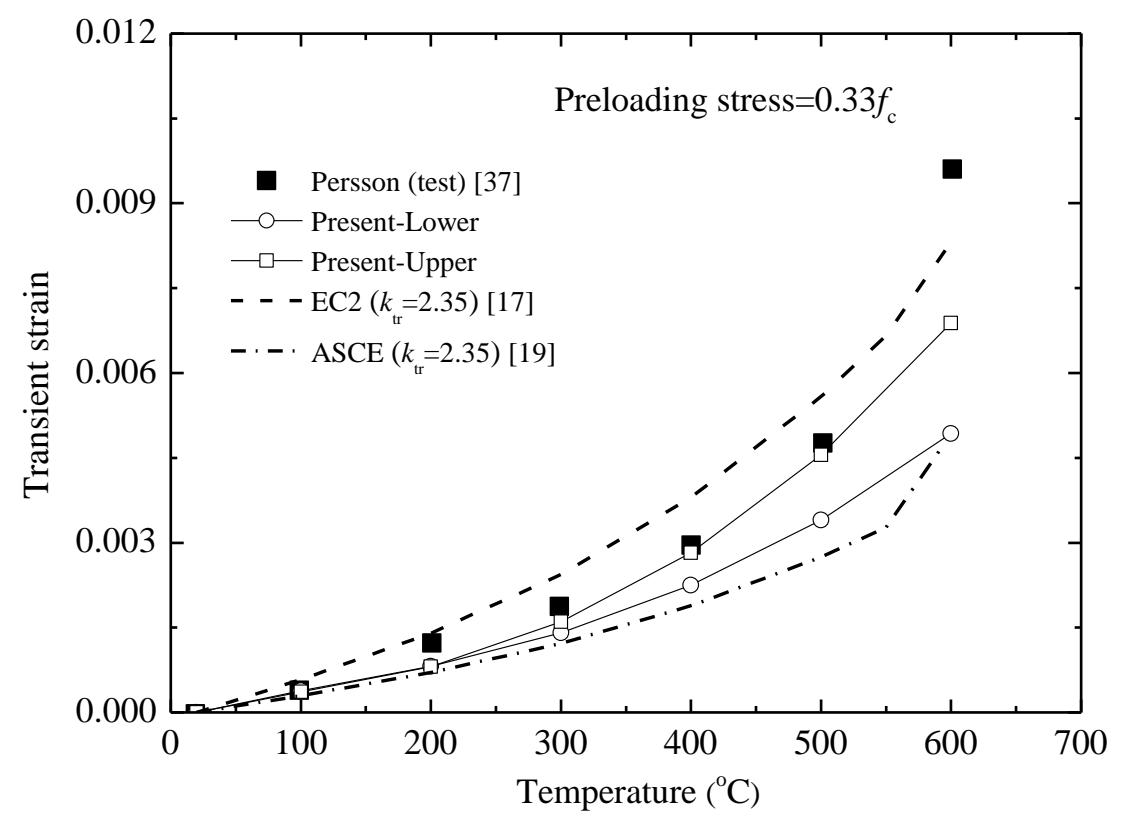

(a) Stress level $=0.33 f_{c}$ 


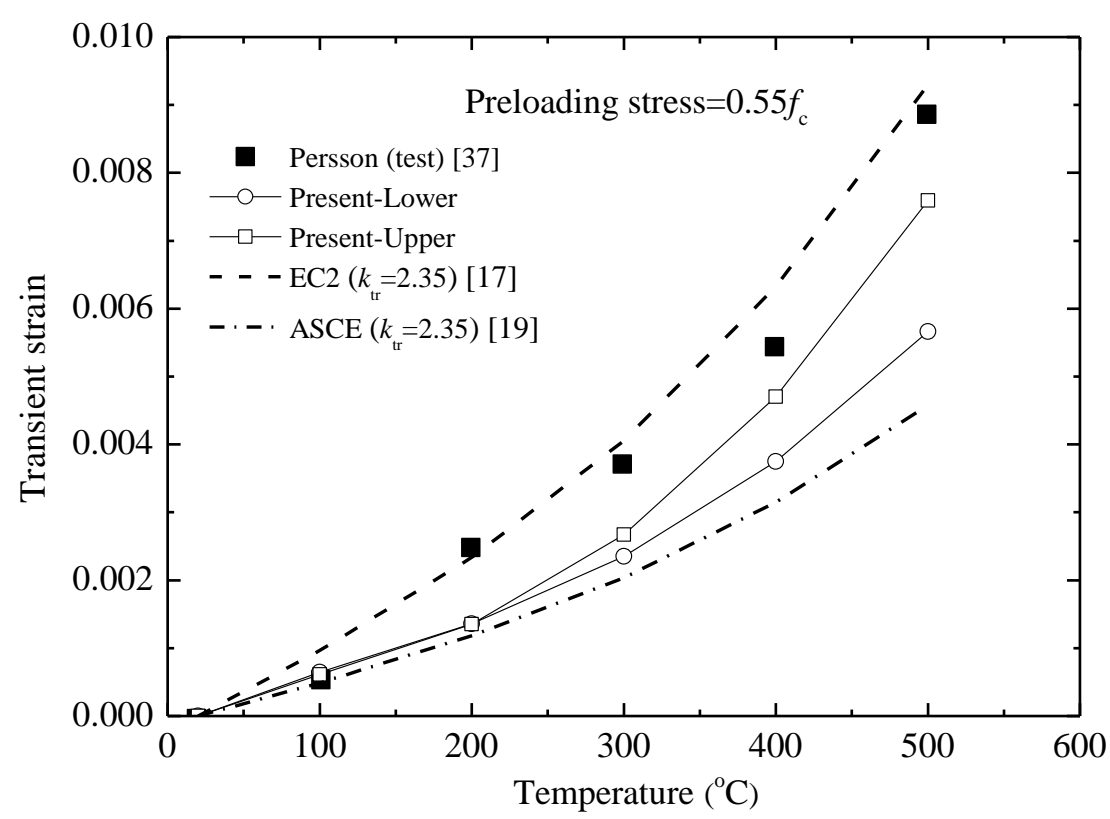

(b) Stress level $=0.55 f_{c}$

Fig. 9 Comparison of the predicted transient strains of the different laws against the test results.

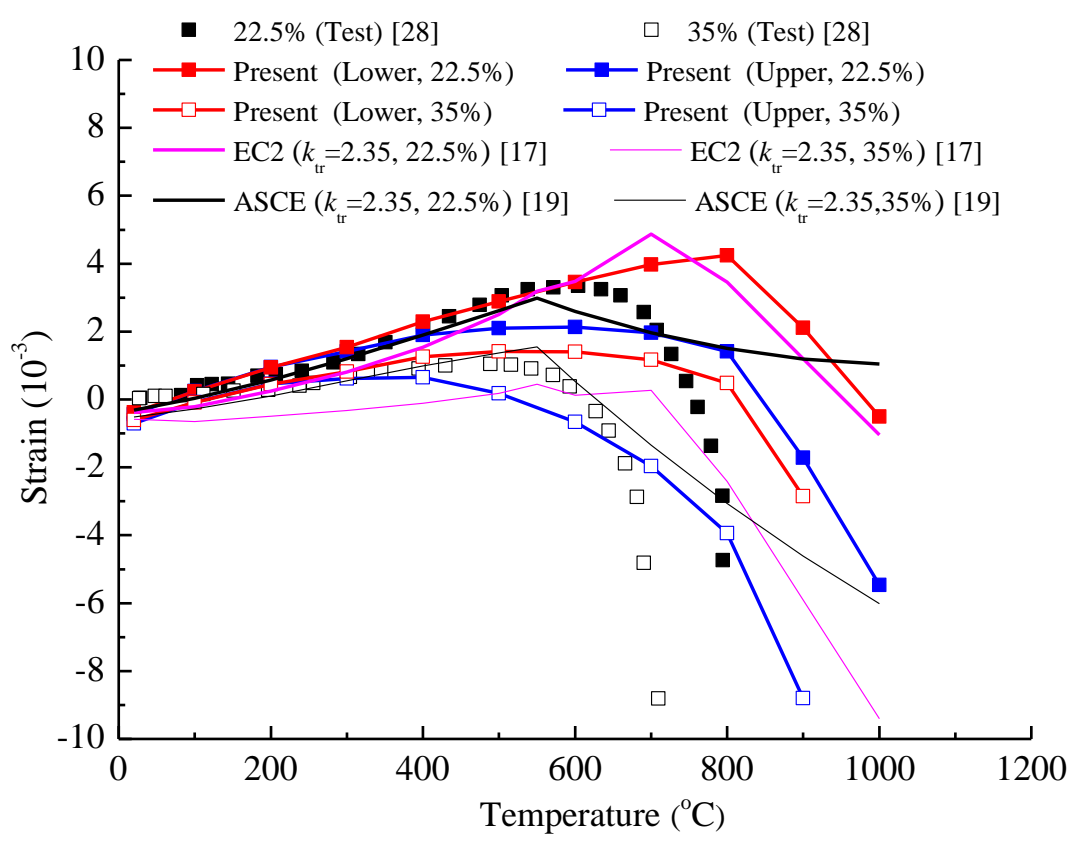

Fig. 10 Predictions of the total concrete strain by different transient strain laws, together with the test results. 


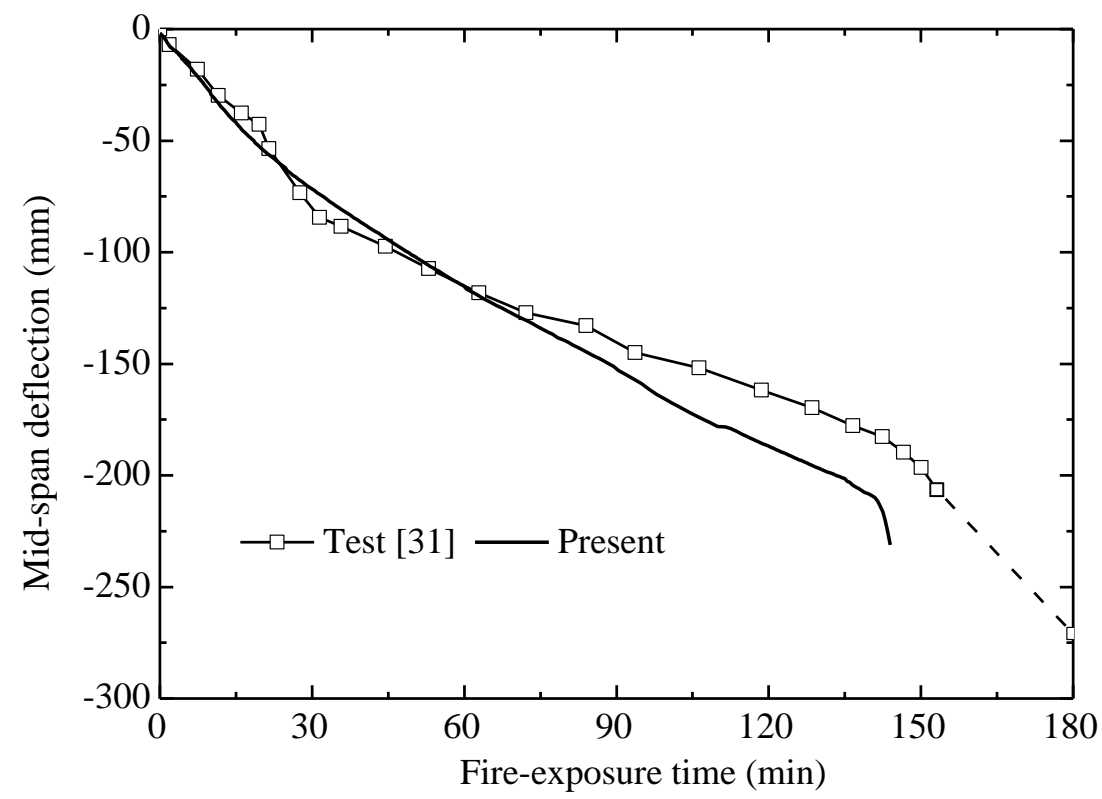

(a)

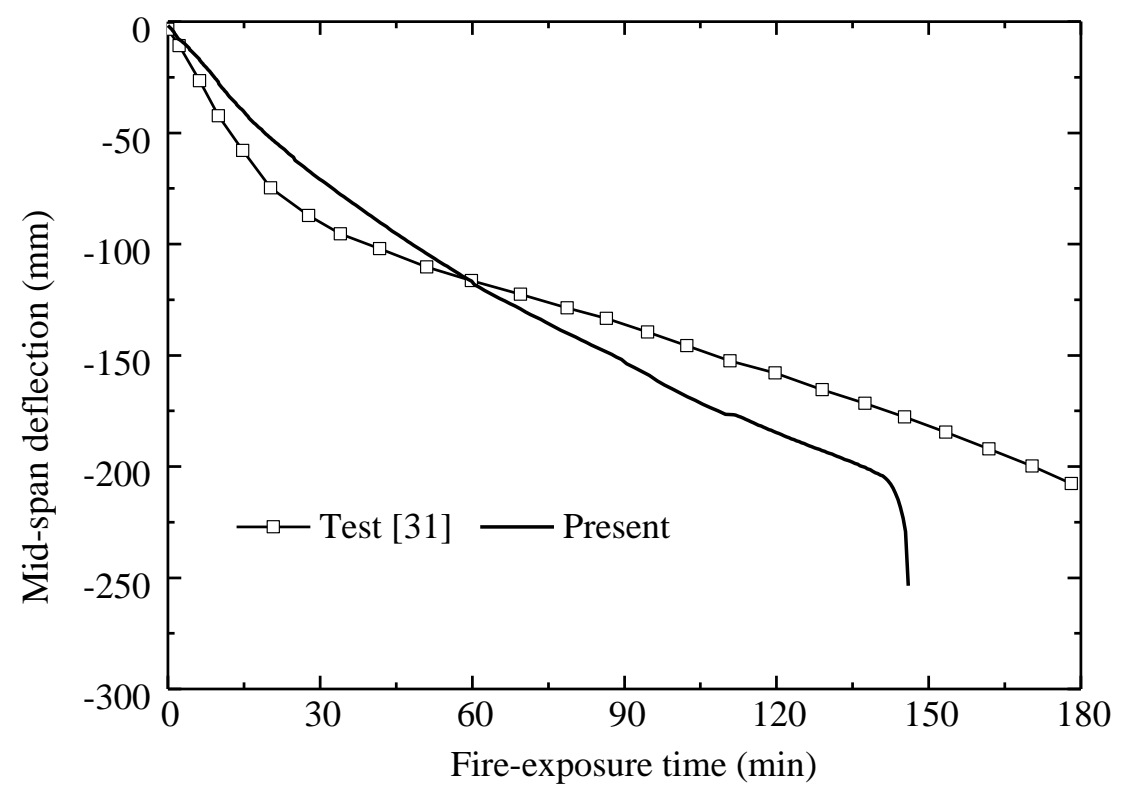

(b)

Fig. 11 Comparison of the tested deflection against the deflection predicted by present model [31]. 


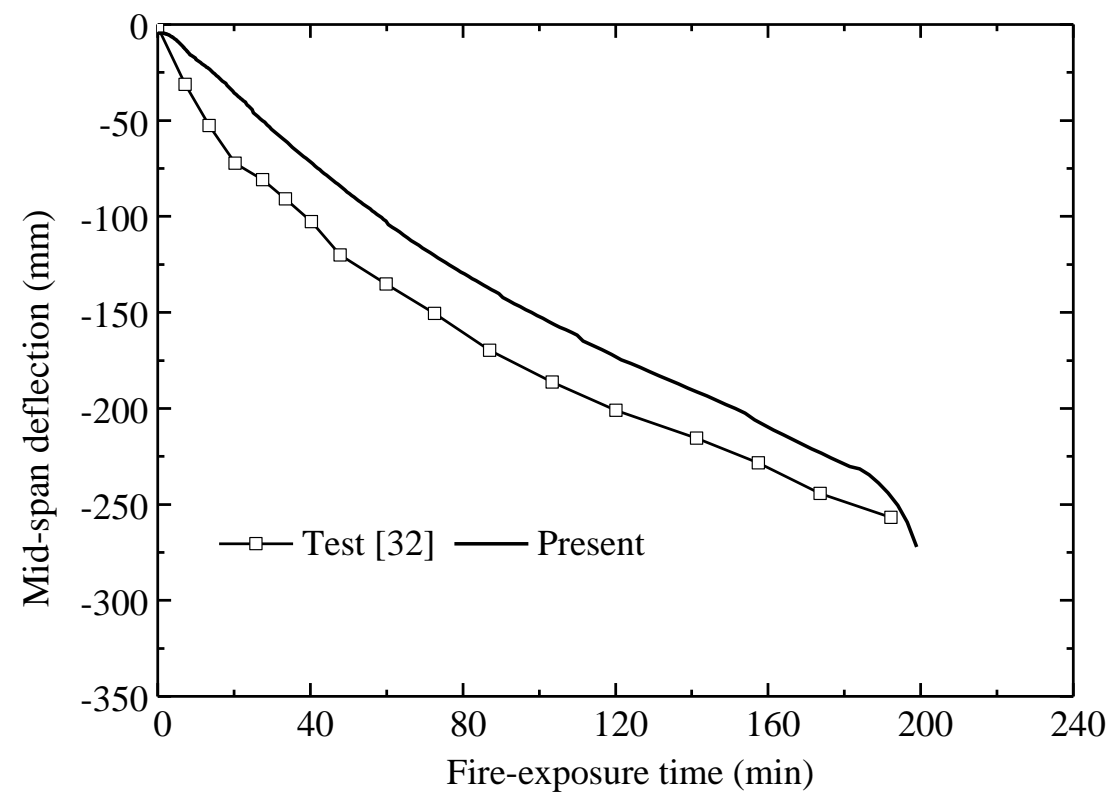

Fig. 12 Comparison of the tested deflection against the deflection predicted by present model [32].

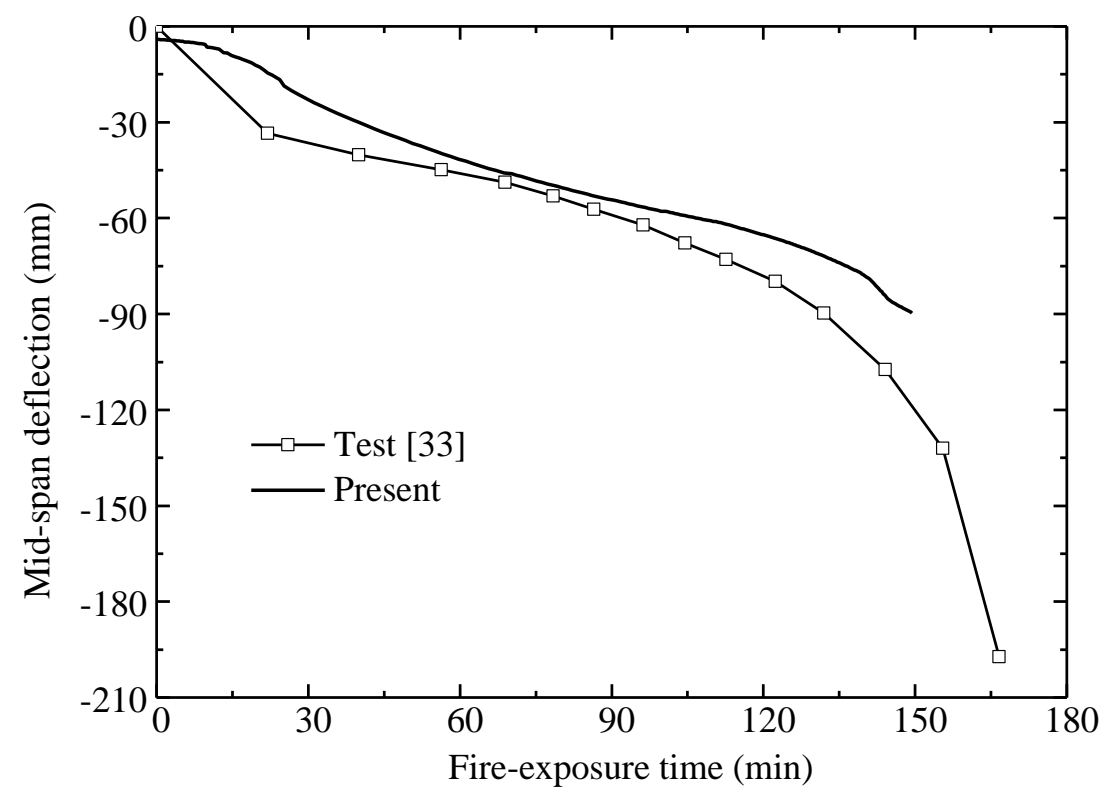

(a) Slab MF1 


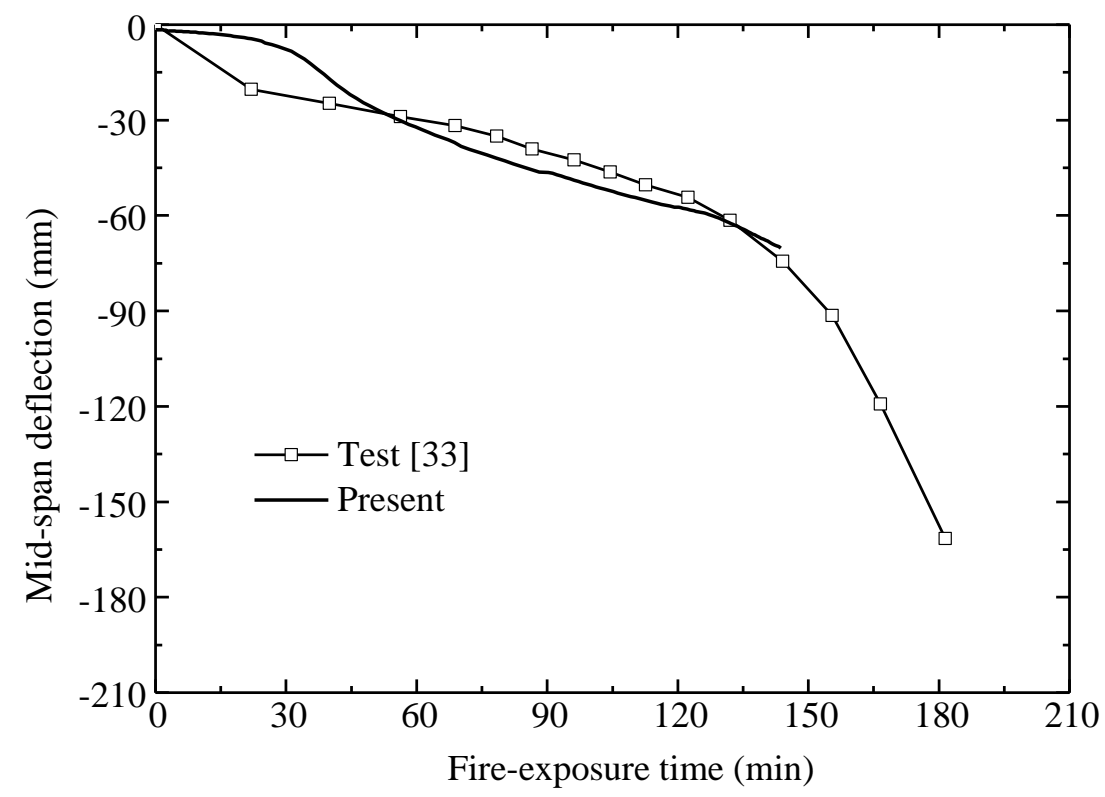

(b) Slab MF2

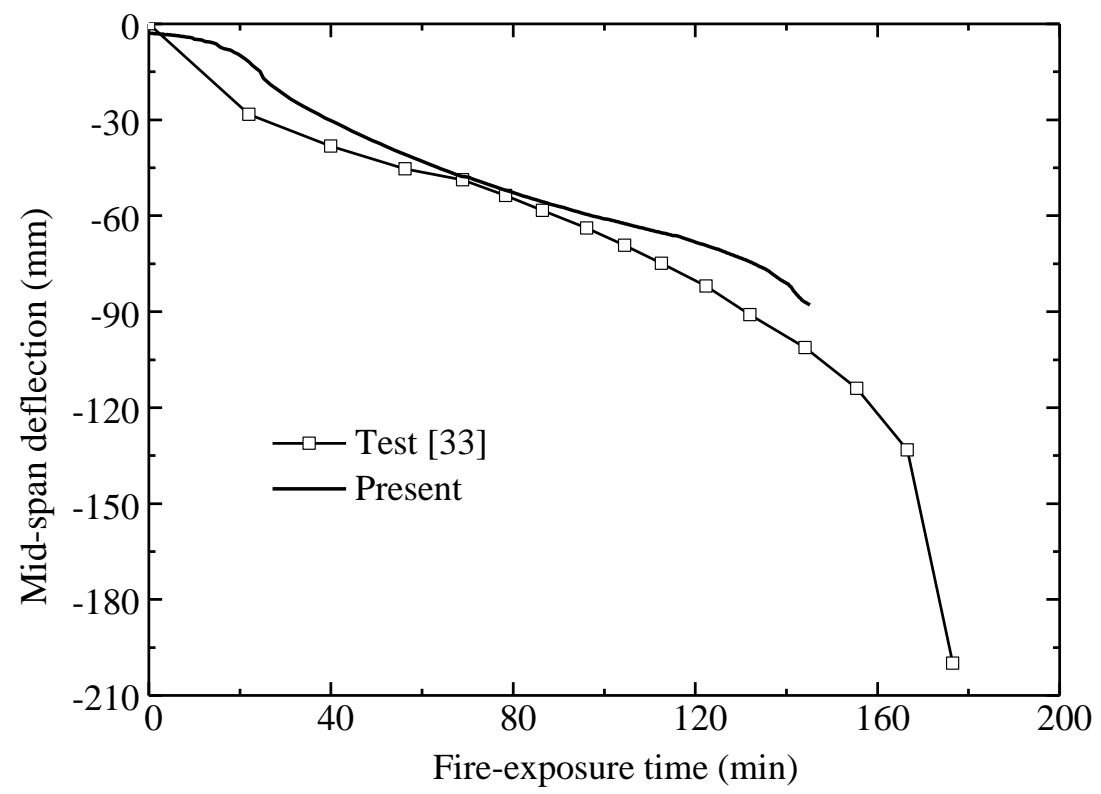

(c) Slab MF3

Fig. 13 Comparison of the tested and predicted deflections of the small-scale slabs [33]. 


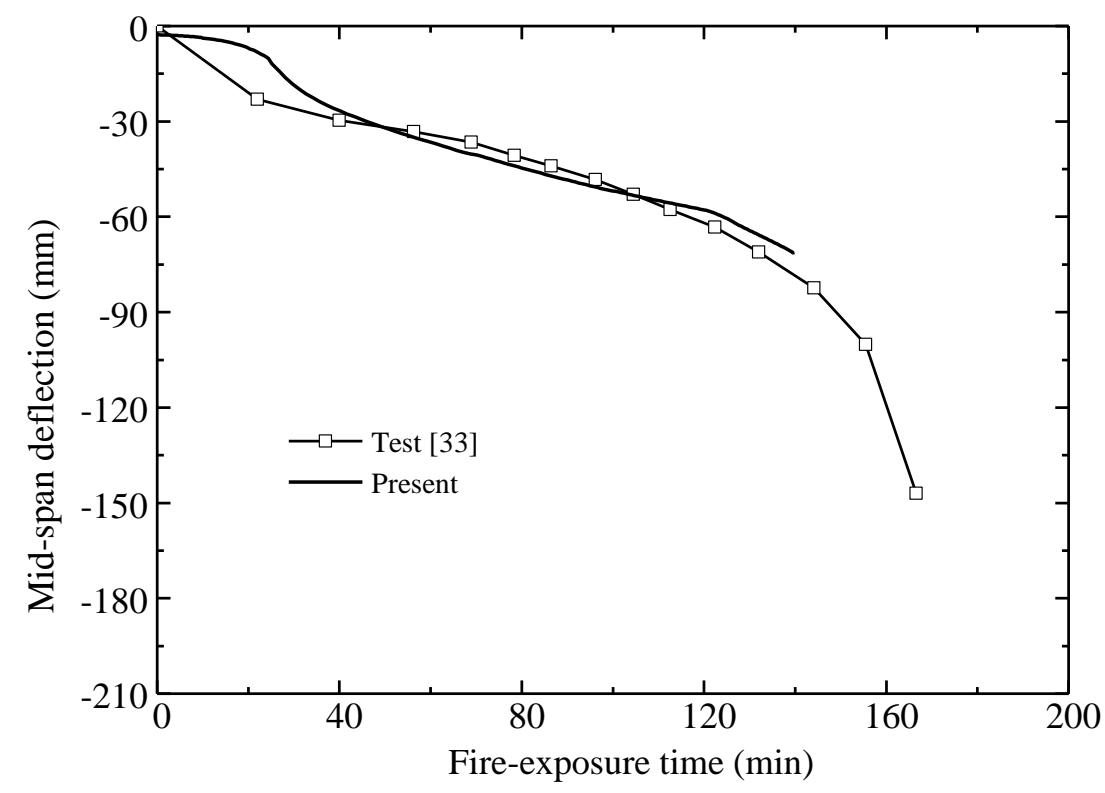

(a) Slab MF4

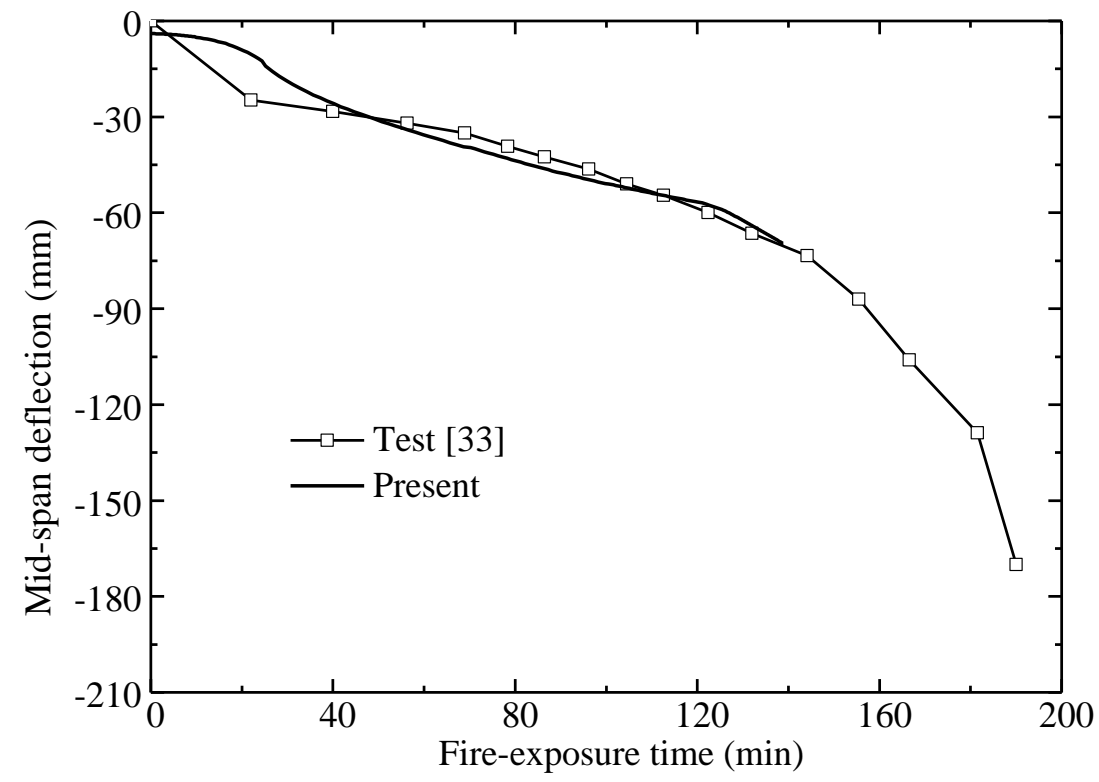

(b) Slab MF6 


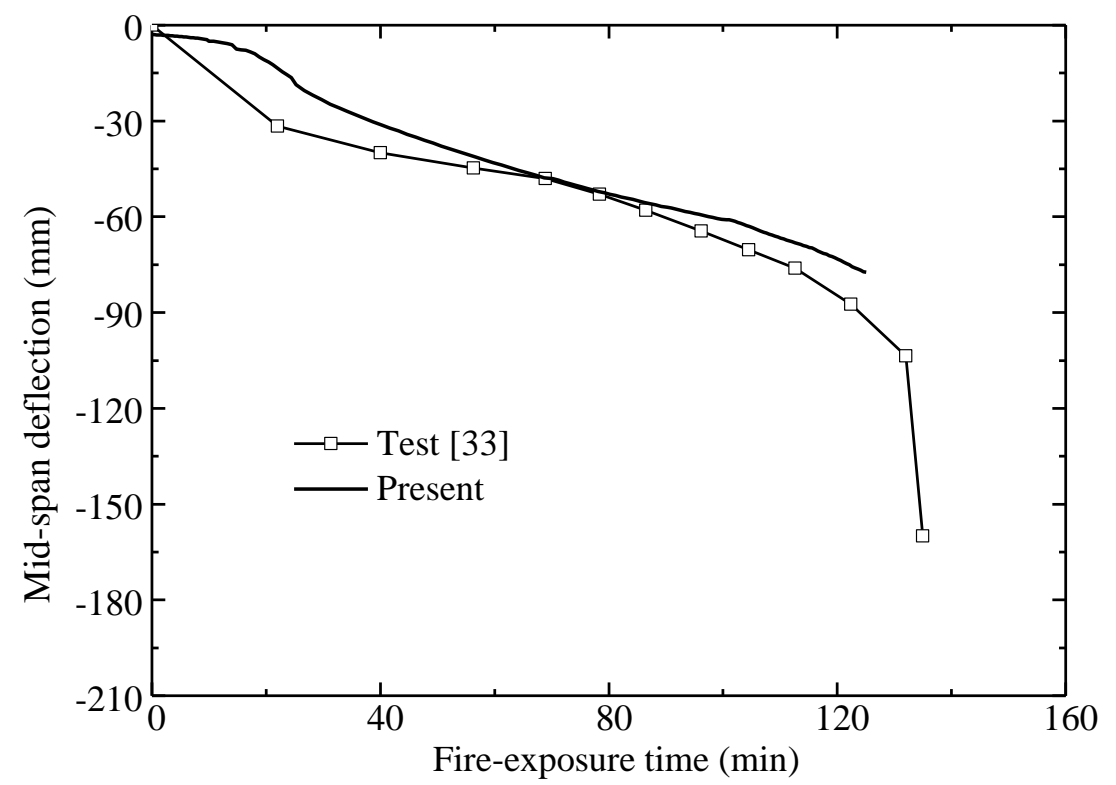

(c) Slab MF7

Fig. 14 Comparison of the tested and predicted deflections of the small-scale slabs [33].

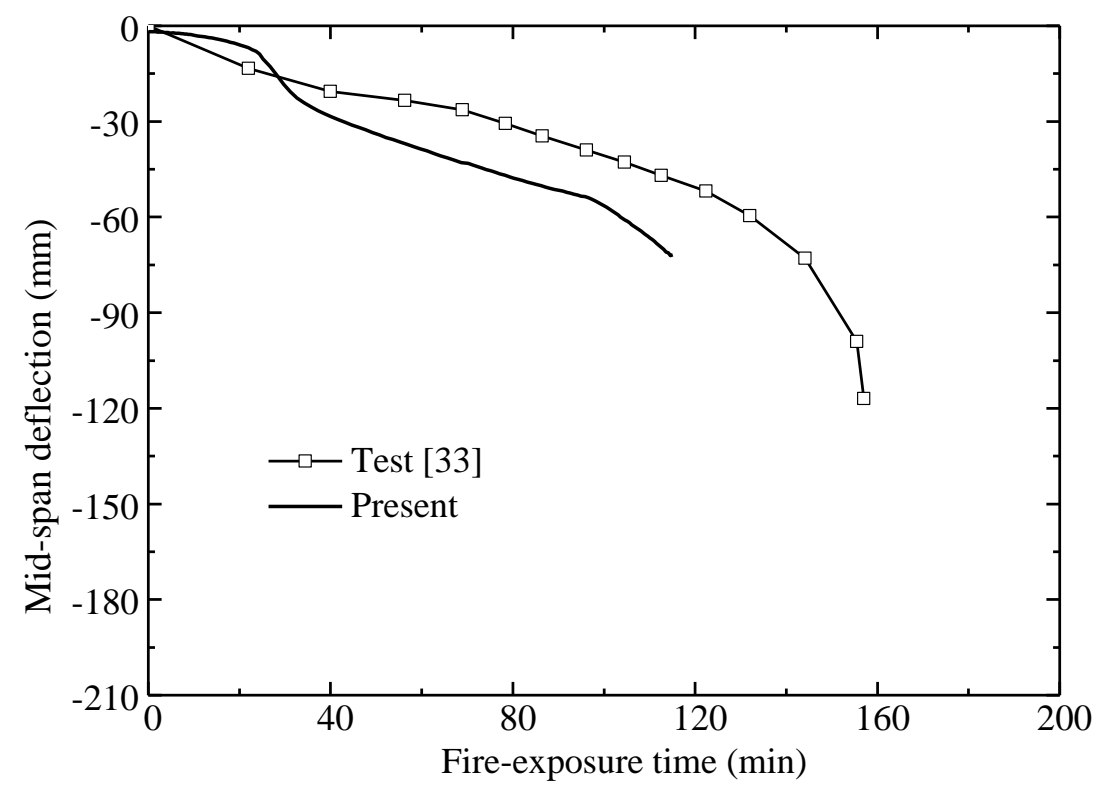

(a) Slab MF8 


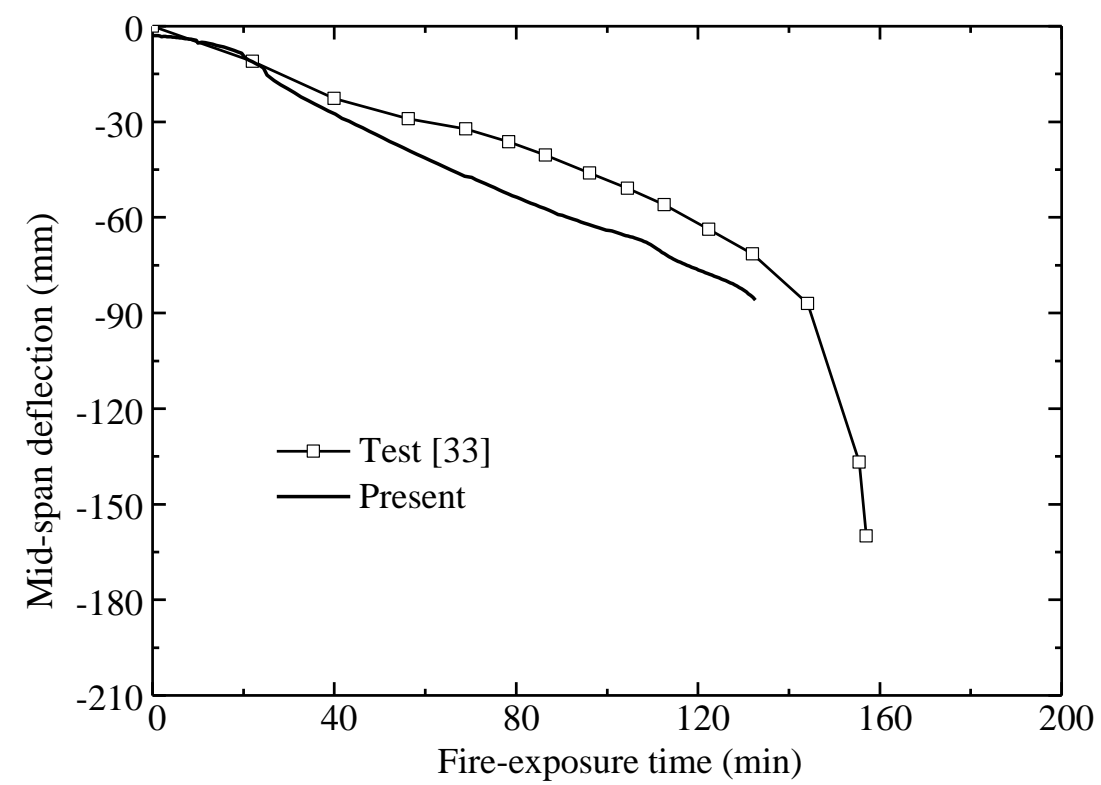

(c) Slab MF9

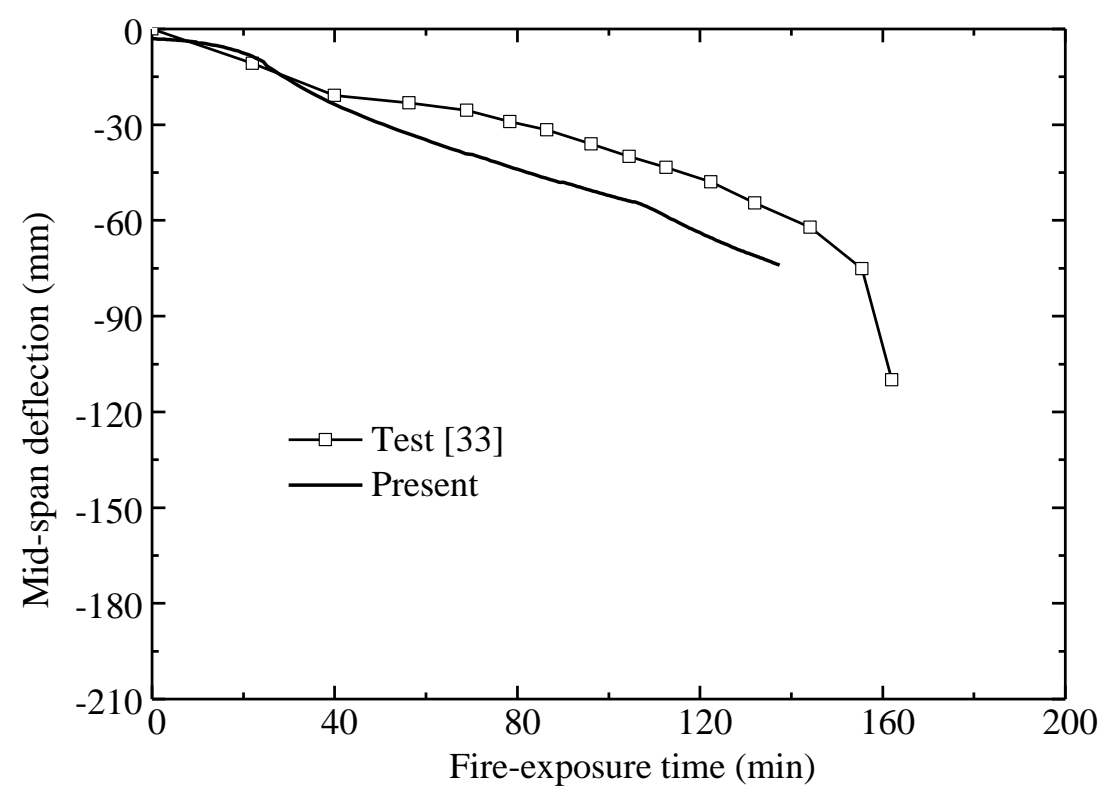

(c) Slab MF10

Fig. 15 Comparison of the tested and predicted deflections of the small-scale slabs [33]. 


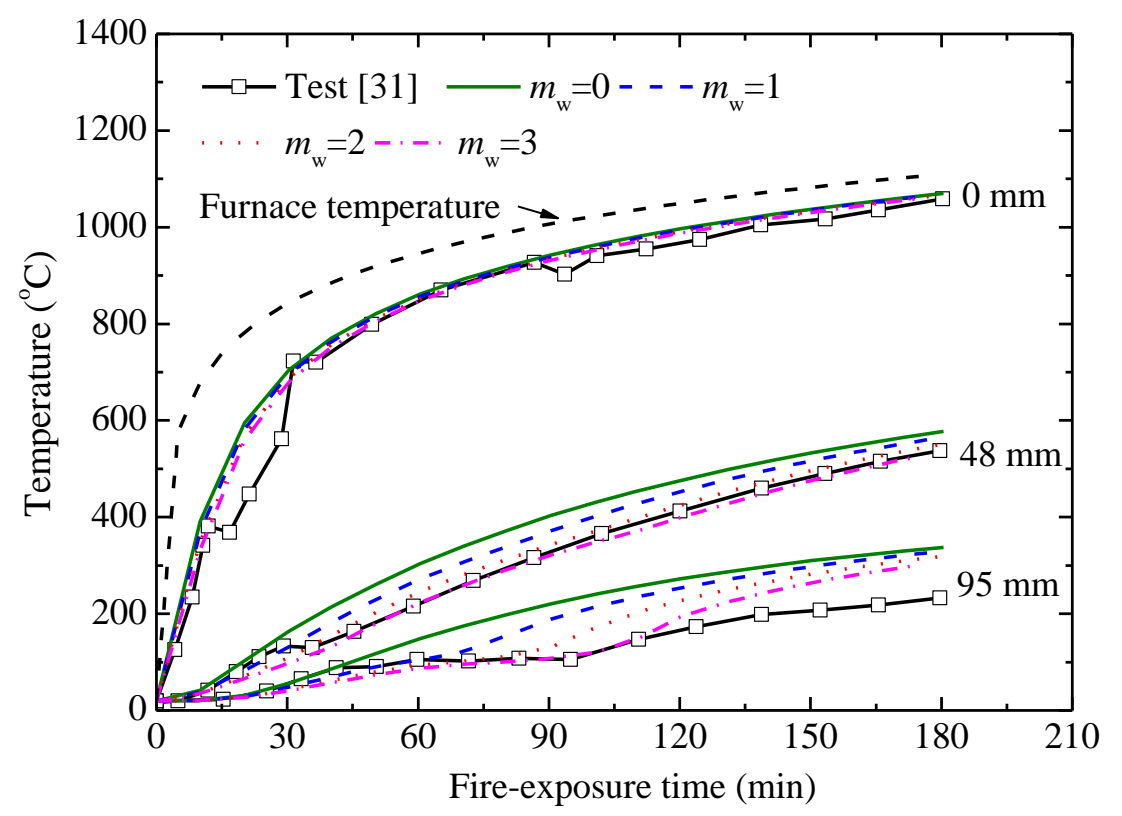

(a) Slab D147

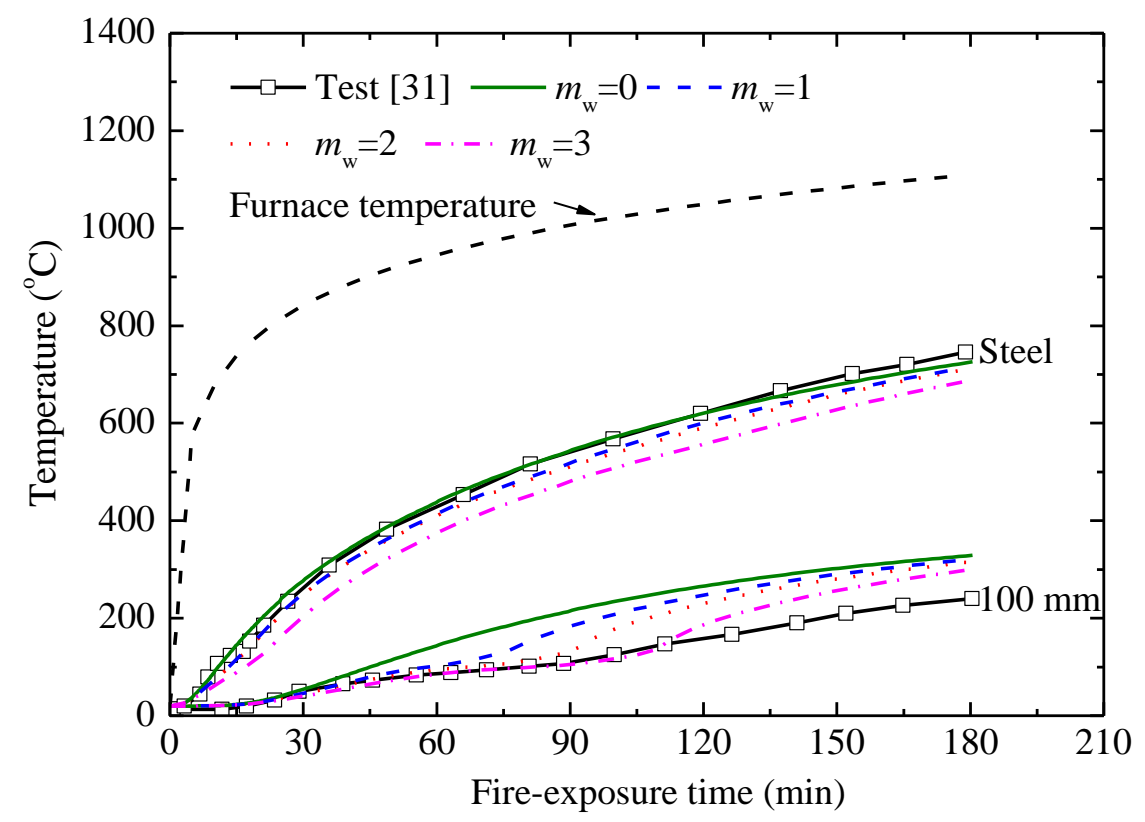

(b) Slab 661 


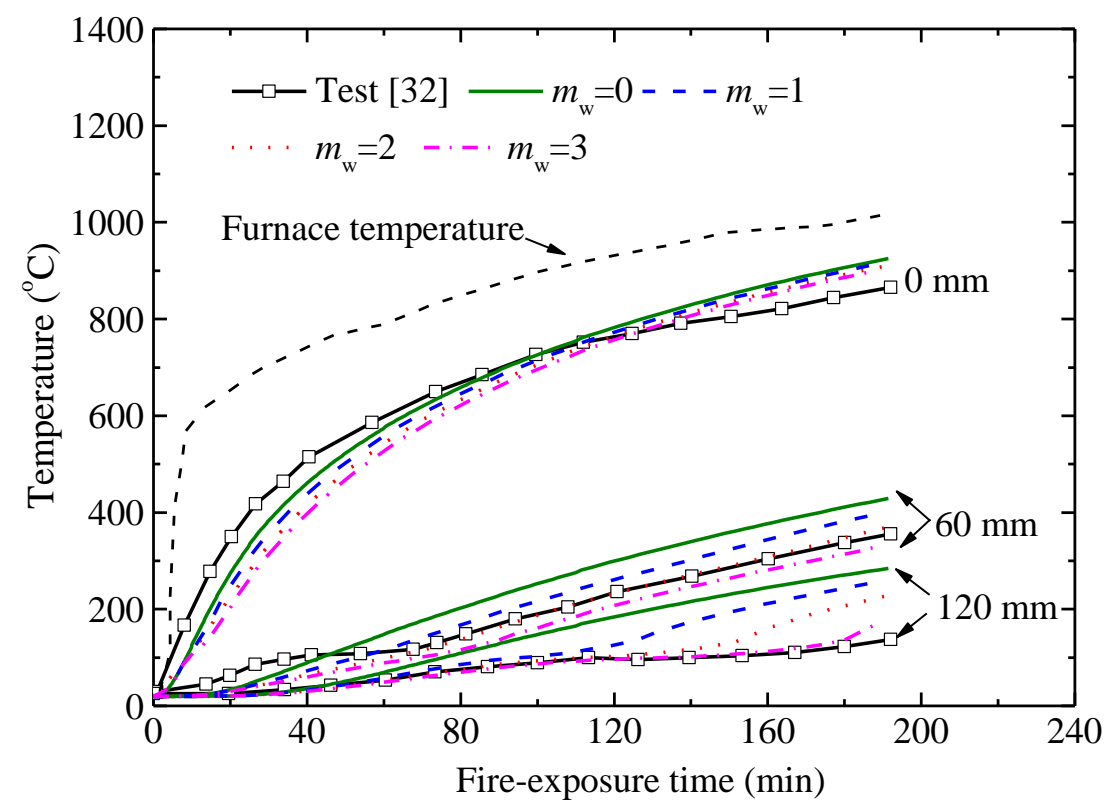

(c) Slab 4ES-2

Fig. 16 The effect of the moisture content on the temperature distributions of the full-scale slab tests.

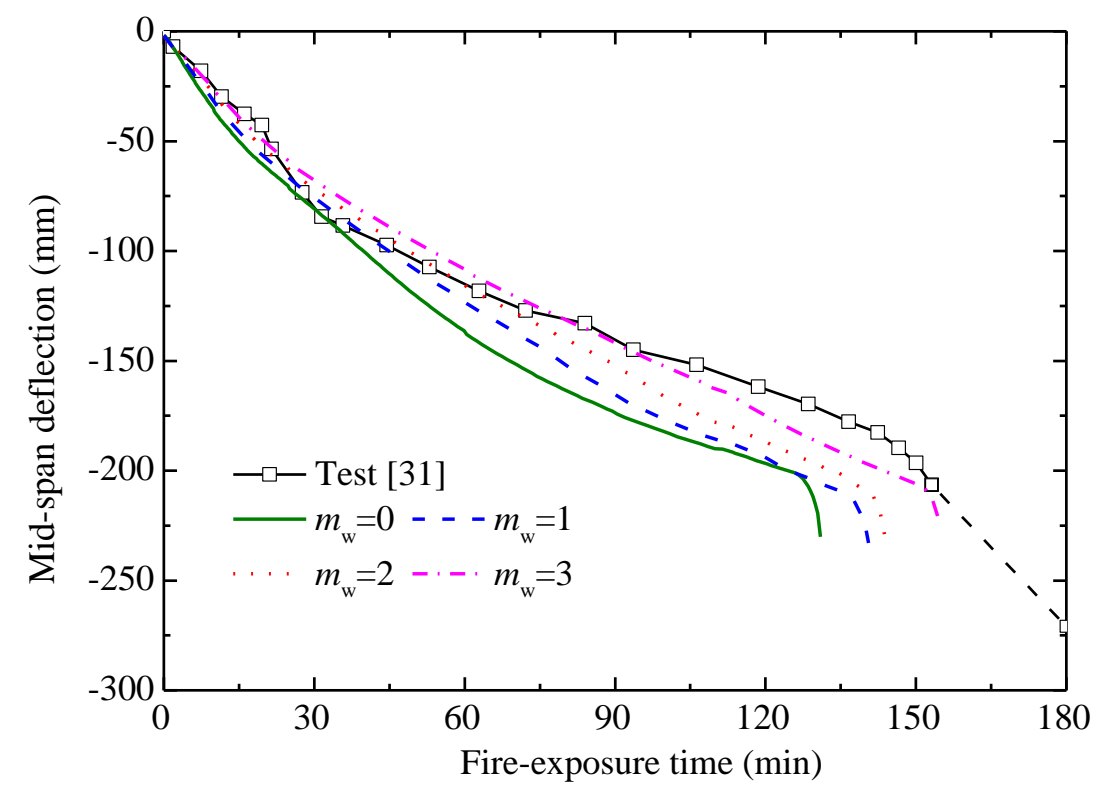

(a) Slab D147 


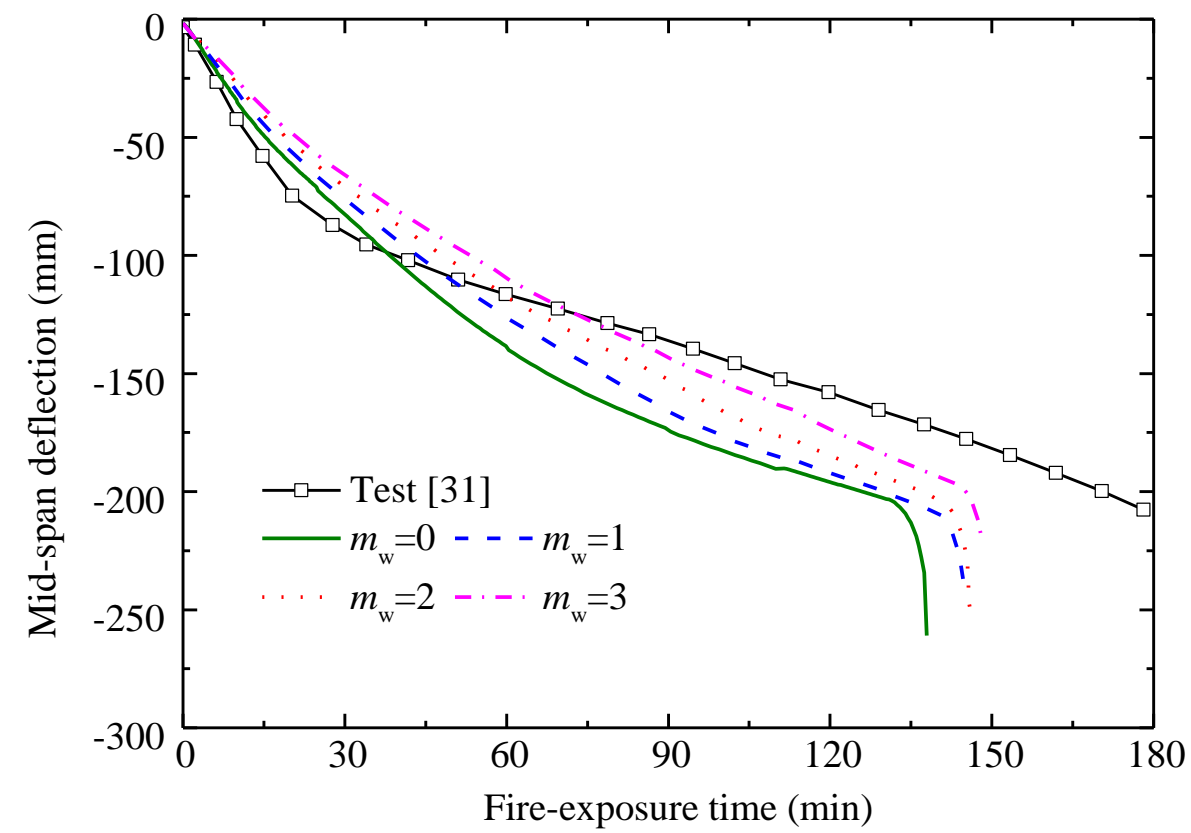

(b) Slab 661

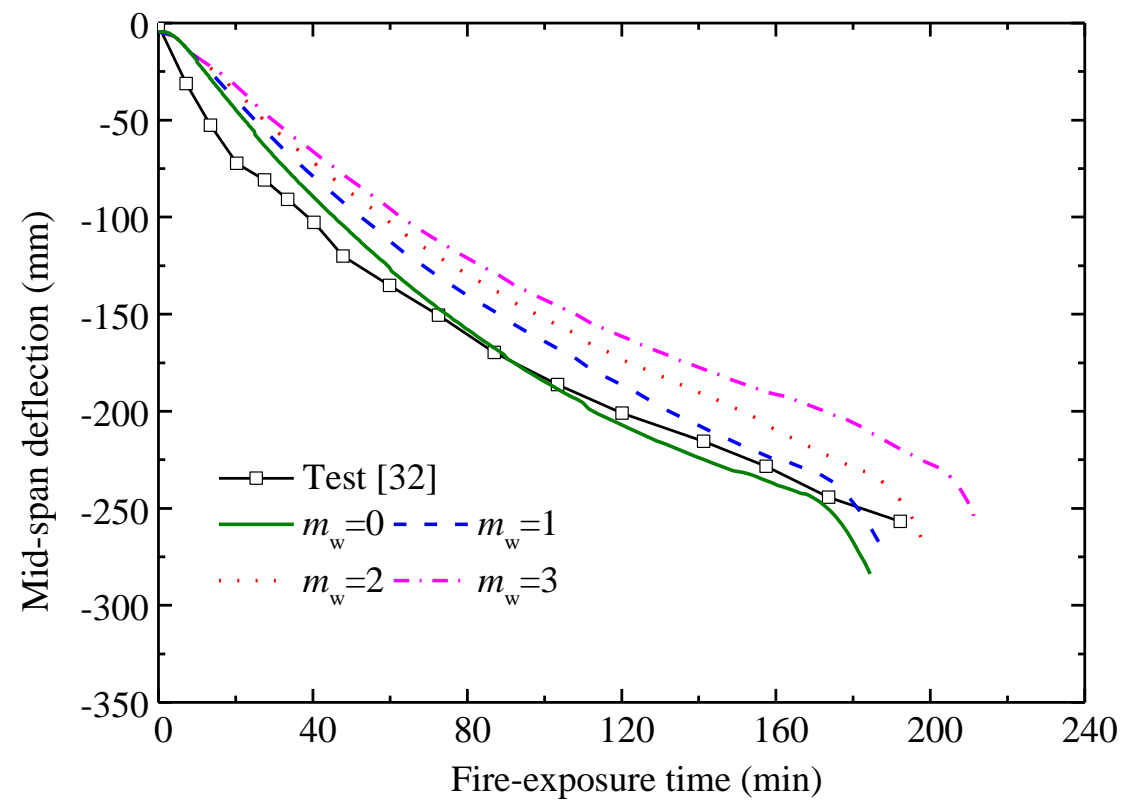

(c) Slab 4ES-2

Fig. 17 The effect of the moisture content on the deflections of the full-scale slab tests. 


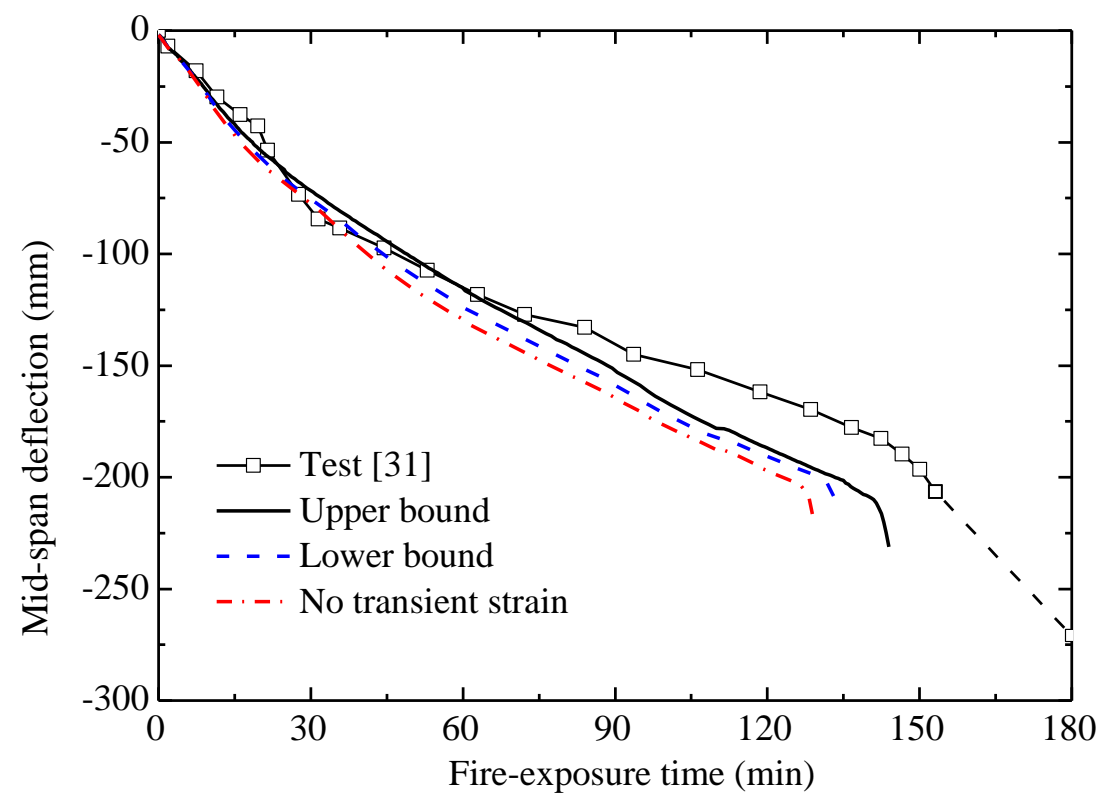

(a) Slab D147

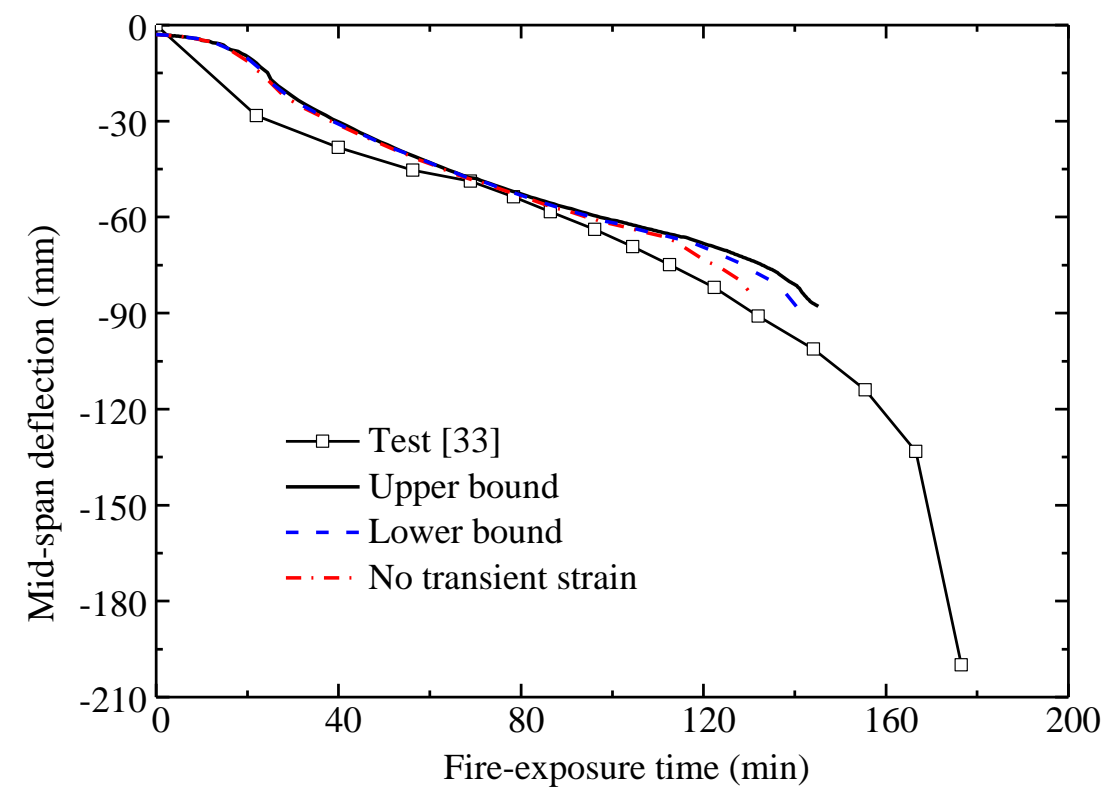

(b) Slab MF3

Fig. 18 Effect of the transient strain on the structural behaviour of the slabs. 


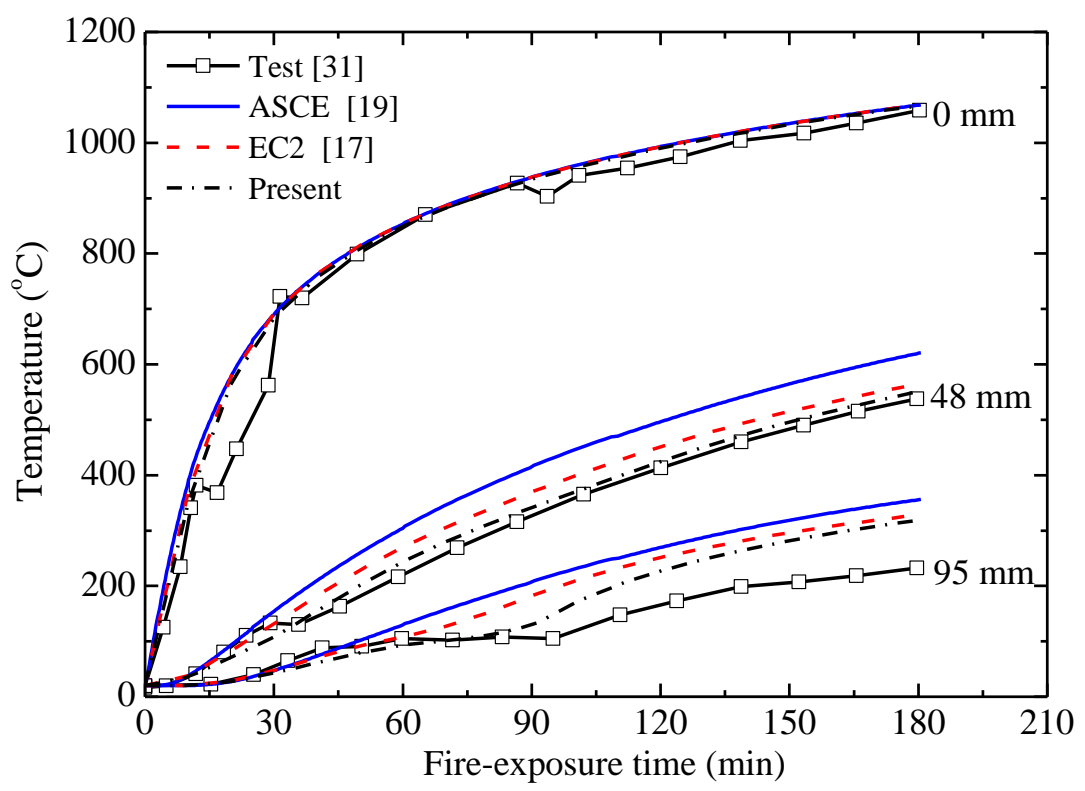

(a) Slab D147 [31]

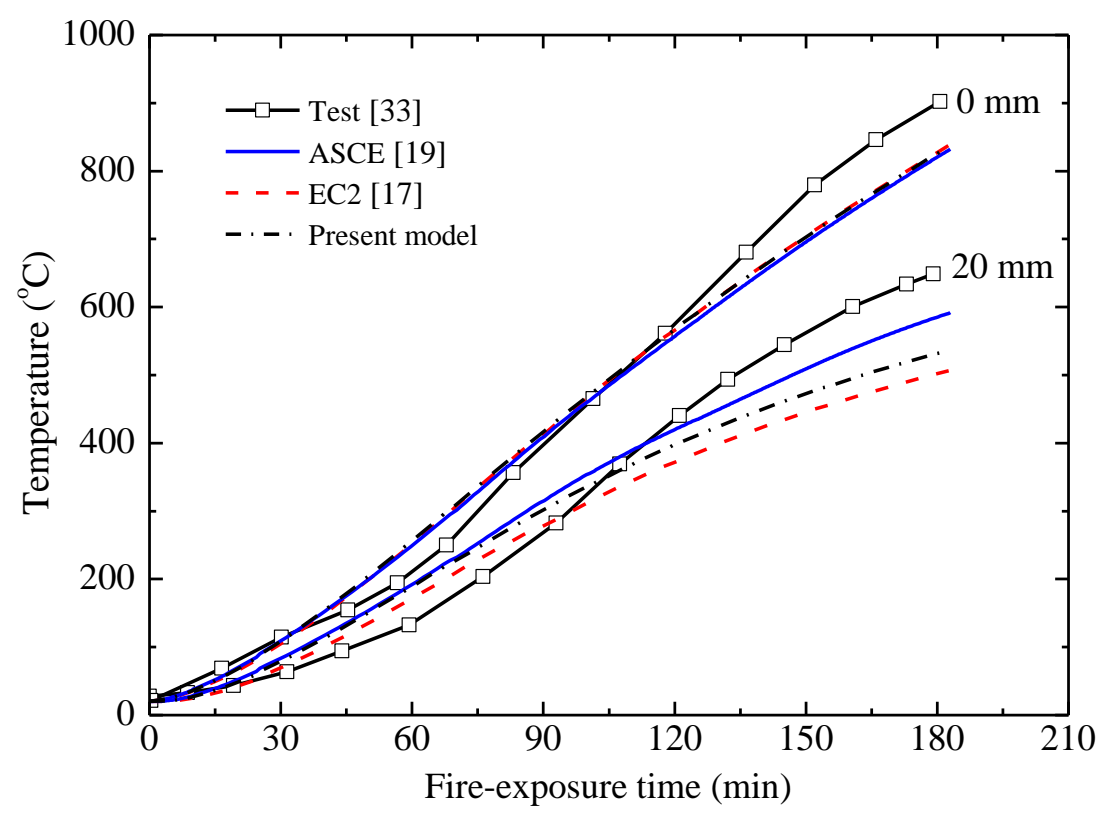

(b) Small-scale slab [33]

Fig. 19 Comparison of the predicted temperatures of the RC-slabs using different concrete thermal laws. 


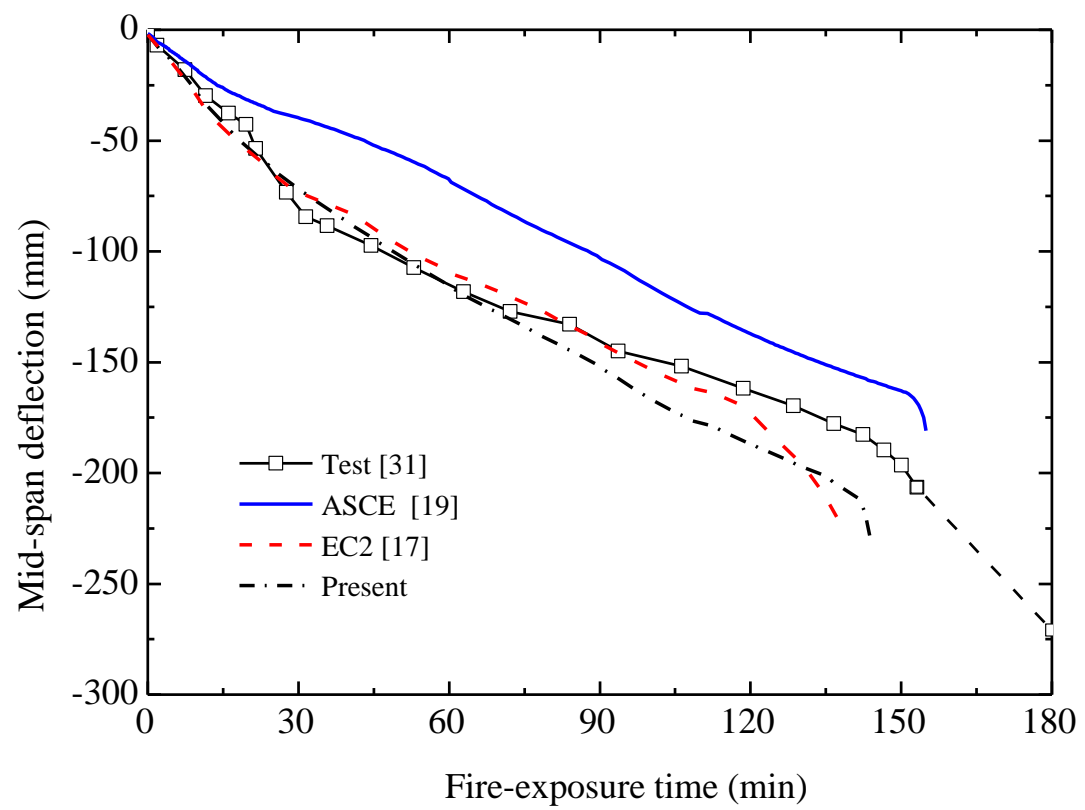

(a) Slab D147 [31]

(b)

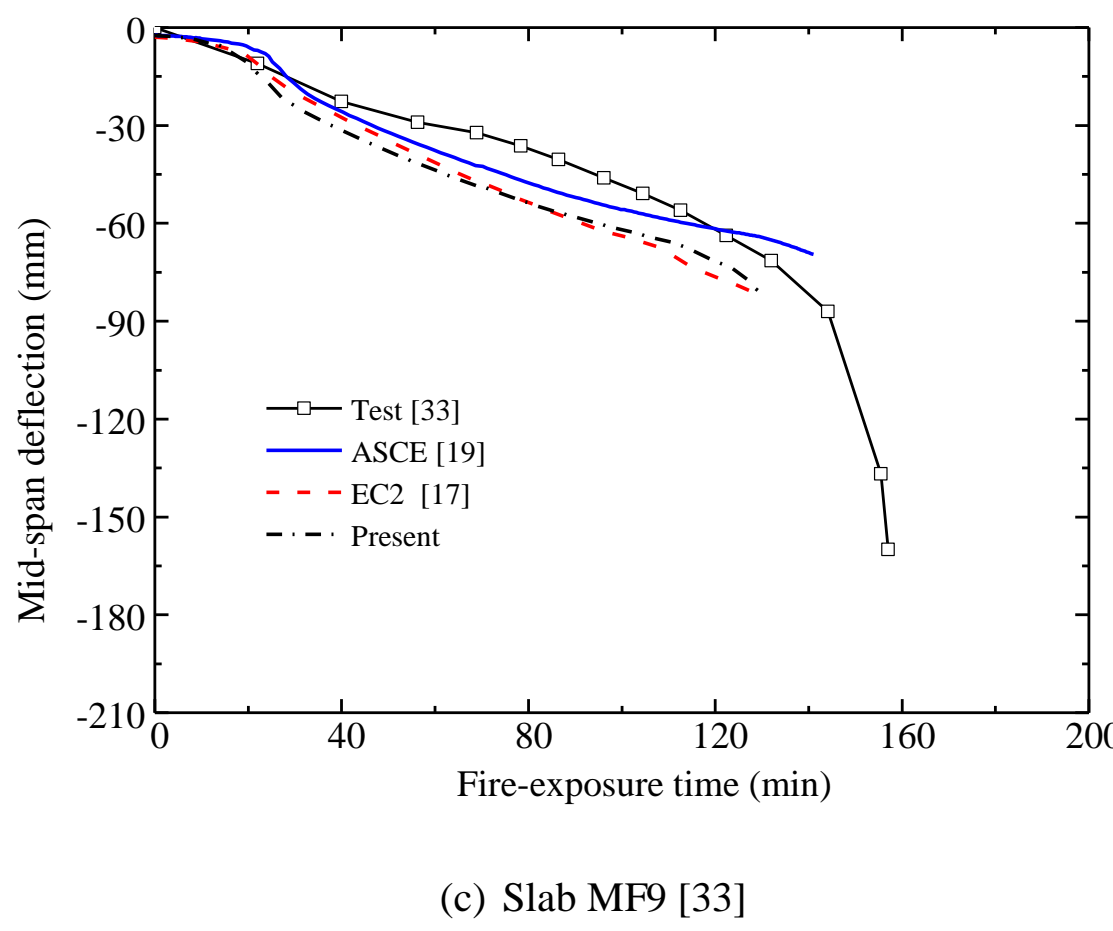

Fig. 20 Comparison of the predicted mid-span deflections of the RC-slabs using different concrete constitutive laws. 


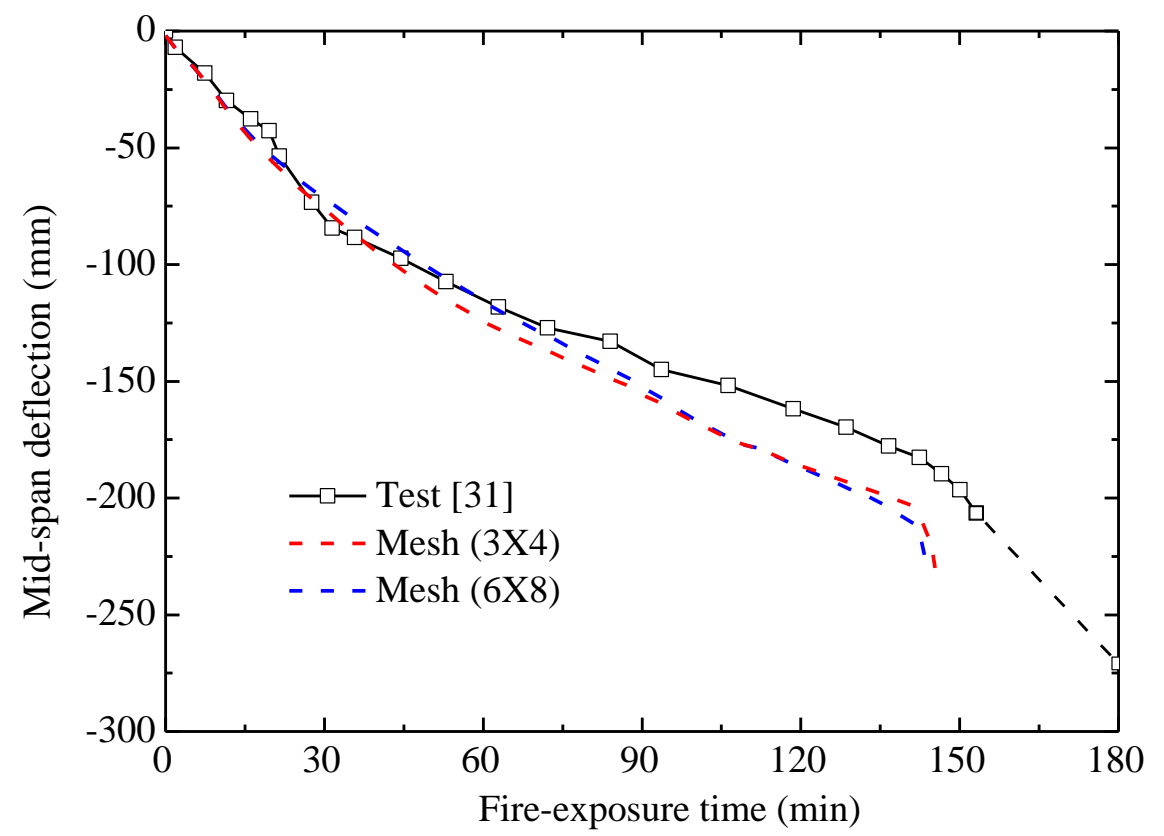

(a) Slab D147 [31]

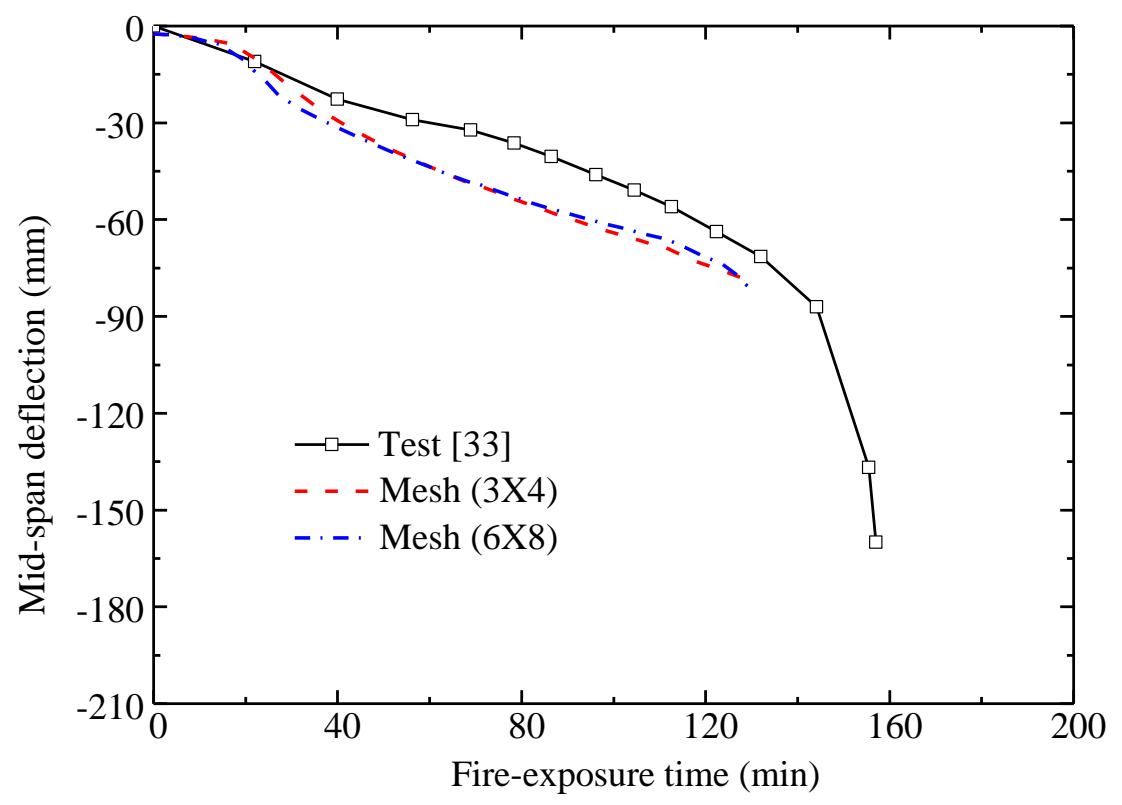

(b) Slab MF9 [33]

Fig. 21 Comparison of the predicted mid-span deflections of the RC-slabs using different mesh sizes. 


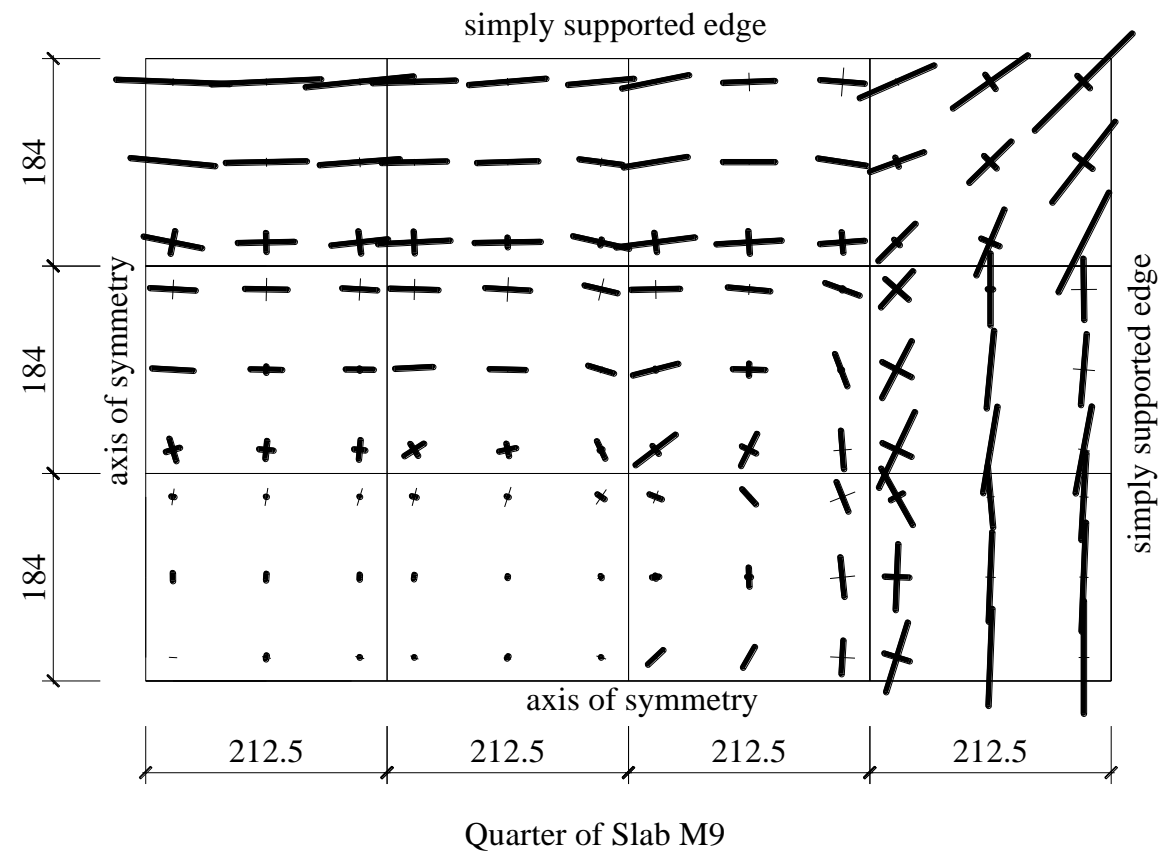

(a) Mesh $3 \times 4$

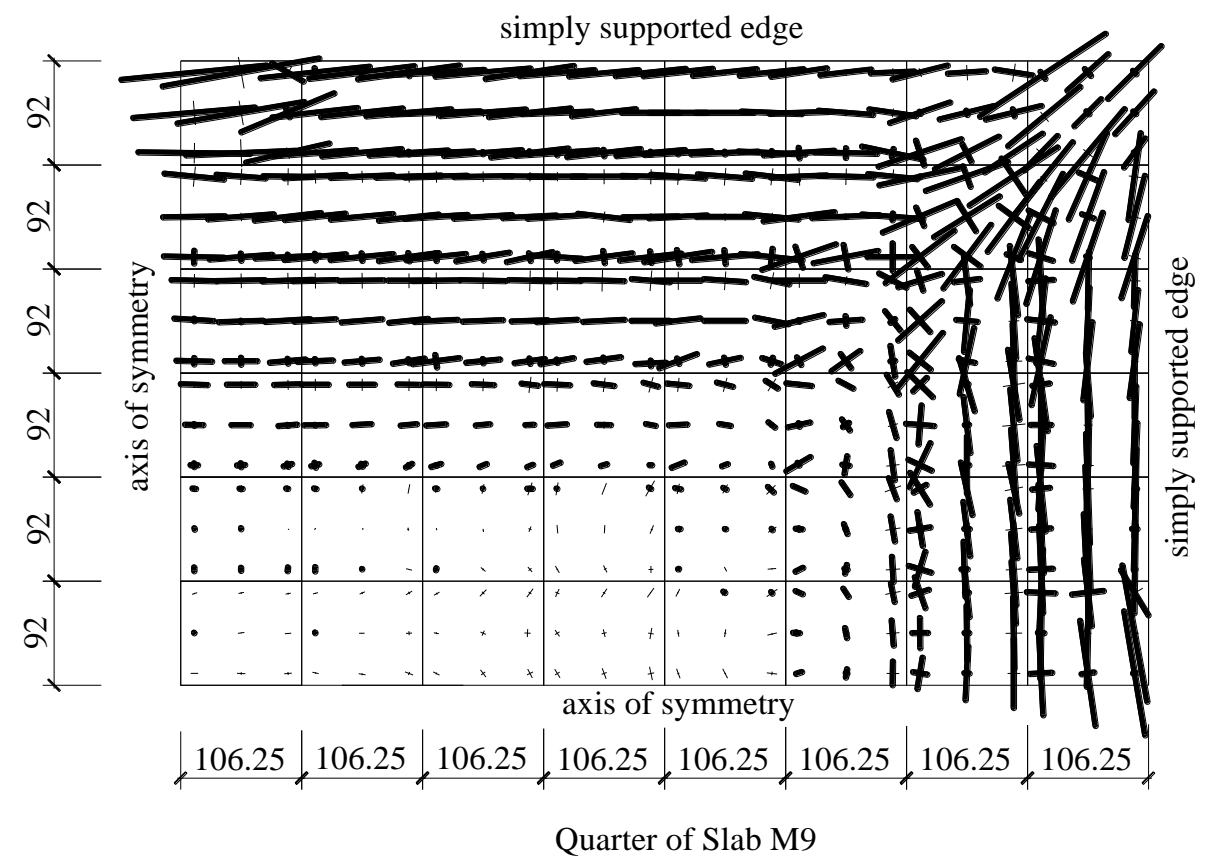

(b) Mesh $6 \times 8$

Fig. 22 Distributions of two principal membrane tractions at Gauss points of slab M9 at 120 min (thick line $=$ compression; thin line $=$ tension $)$. 